\title{
Low back pain
}

Citation for published version (APA):

Vlaeyen, J. W. S., Maher, C. G., Wiech, K., Van Zundert, J., Meloto, C. B., Diatchenko, L., Battié, M. C., Goossens, M., Koes, B., \& Linton, S. J. (2018). Low back pain. Nature Reviews Disease Primers, 4, [52]. https://doi.org/10.1038/s41572-018-0052-1

Document status and date:

Published: 13/12/2018

DOI:

10.1038/s41572-018-0052-1

Document Version:

Publisher's PDF, also known as Version of record

\section{Document license:}

Taverne

\section{Please check the document version of this publication:}

- A submitted manuscript is the version of the article upon submission and before peer-review. There can be important differences between the submitted version and the official published version of record.

People interested in the research are advised to contact the author for the final version of the publication, or visit the DOI to the publisher's website.

- The final author version and the galley proof are versions of the publication after peer review.

- The final published version features the final layout of the paper including the volume, issue and page numbers.

Link to publication

\footnotetext{
General rights rights.

- You may freely distribute the URL identifying the publication in the public portal. please follow below link for the End User Agreement:

www.umlib.nl/taverne-license

Take down policy

If you believe that this document breaches copyright please contact us at:

repository@maastrichtuniversity.nl

providing details and we will investigate your claim.
}

Copyright and moral rights for the publications made accessible in the public portal are retained by the authors and/or other copyright owners and it is a condition of accessing publications that users recognise and abide by the legal requirements associated with these

- Users may download and print one copy of any publication from the public portal for the purpose of private study or research.

- You may not further distribute the material or use it for any profit-making activity or commercial gain

If the publication is distributed under the terms of Article $25 \mathrm{fa}$ of the Dutch Copyright Act, indicated by the "Taverne" license above, 
Low back pain

Johan W. S. Vlaeyen ${ }^{1,2,3 *}$, Chris G. Maher ${ }^{4}$, Katja Wiech ${ }^{5,6}$, Jan Van Zundert ${ }^{7,8}$, Carolina Beraldo Meloto ${ }^{9}$, Luda Diatchenko ${ }^{9}$, Michele C. Battié ${ }^{10}$, Marielle Goossens ${ }^{2,11}$, Bart Koes ${ }^{12,13}$ and Steven J. Linton ${ }^{14}$

Abstract | Low back pain affects individuals of all ages and is a leading contributor to disease burden worldwide. Despite advancements in assessment and treatment methods, the management of low back pain remains a challenge for researchers and clinicians alike. One reason for the limited success in identifying effective treatments is the large variation in the manifestations, possible causes, precipitating and maintaining factors, course, prognosis and consequences in terms of activity interference and quality of life. However, despite these challenges, steady progress has been achieved in the understanding of back pain, and important steps in the understanding of the psychological and social risk factors, genetics and brain mechanisms of low back pain have been made. These new findings have given impetus to the development of new diagnostic procedures, evidence-based screening methods and more targeted interventions, which underscore the need for a multidisciplinary approach to the management of low back pain that integrates biological, psychological and social aspects.

Chronic pain is one of the most costly and prevalent sources of human suffering, especially in, but not limited to, modern industrialized societies. Low back pain is normally considered as pain, muscle tension or stiffness localized below the costal margin and above the inferior gluteal folds, with or without sciatica (pain travelling down the leg from the lower back). Almost everyone has a brief, acute episode of low back pain during their lifetime. Although many people with back pain recover within 1 year, some will develop a chronic condition with fluctuating or persisting pain of low or medium intensity, interrupted by periods of no pain or pain exacerbation $^{1}$. When back pain persists for $>3$ months, it is (by consensus) no longer considered as a symptom but as a disorder in itself that is maintained by factors that might be different from the initiating causes. Chronic back pain can be associated with functional disability and work incapacity, and can affect quality of life. Often, back pain does not occur in isolation, as many individuals with back pain also report pain in other regions of the body. A higher number of painful body regions is associated with higher functional disability, more work absences, more severe feelings of depression and anxiety and reduced quality of life ${ }^{2,3}$. The large majority of patients with back pain have nonspecific pain, whereby an underlying pathology or a nociceptive contributor has not been identified ${ }^{4}$.

The societal and economic costs of back pain are high, and indirect costs are usually higher than direct medical costs. In Australia, the total cost for low back pain was estimated at AUD\$9 billion in 2001, but only
$11 \%$ of this amount was accounted for by direct healthcare costs ${ }^{5,6}$. Similar proportions have been observed in the Netherlands and the United Kingdom ${ }^{7-9}$. Although the costs associated with back pain in the Netherlands have reduced from $€ 4.3$ billion in 2002 to $€ 3.5$ billion in 2007, the costs are still substantial and constituted $0.6 \%$ of the gross national product in 2007 . In all these estimates, the majority of costs were attributed to productivity losses.

Traditionally, back pain was considered as a result of injury (the so-called injury model). This model is overly simplistic; the association is modest between physical loads with structural degenerative changes and pathology of the vertebral column or supporting structures, and pathological findings have been observed in asymptomatic individuals. A biopsychosocial model of back pain has been developed in which biological factors with modest effect sizes interacting with other risk factors are likely to contribute to the development of chronic back pain. The non-biological risk factors include negative beliefs and expectations about pain, emotional responses, pain behaviours, perceptions about the relationship between pain, health and work and societal obstacles.

In the International Classification of Diseases 10th revision (ICD-10), diagnostic codes for pain conditions, including low back pain, are included but do not account for the heterogeneity of chronic back pain in particular. Thus, a new classification of chronic pain has been developed for ICD-11 (REF. ${ }^{10}$ ), in which chronic back pain is classified under a new entity, 'chronic primary pain'. 


\author{
Author addresses \\ ${ }^{1}$ Research Group Health Psychology, University of Leuven, Leuven, Belgium. \\ ${ }^{2}$ Research Group Experimental Health Psychology, Maastricht University, Maastricht, \\ Netherlands. \\ ${ }^{3}$ TRACE Center for Translational Health Research, KU Leuven — Ziekenhuis \\ Oost-Limburg, Genk, Belgium. \\ ${ }^{4}$ Sydney School of Public Health, Faculty of Medicine and Health, The University of \\ Sydney, Camperdown, New South Wales, Australia. \\ ${ }^{5}$ Wellcome Centre for Integrative Neuroimaging, University of Oxford, John Radcliffe \\ Hospital, Oxford, UK. \\ ${ }^{6}$ Nuffield Department of Clinical Neurosciences, Nuffield Division Anaesthetics, \\ University of Oxford, John Radcliffe Hospital, Oxford, UK. \\ ${ }^{7}$ Department of Anesthesiology, Critical Care and Multidisciplinary Pain Center, \\ Ziekenhuis Oost-Limburg, Genk, Belgium. \\ ${ }^{8}$ Department of Anesthesiology and Pain Medicine, Maastricht University Medical \\ Center, Maastricht, Netherlands. \\ ${ }^{9}$ The Alan Edwards Centre for Research on Pain, McGill University, Montreal, Quebec, \\ Canada. \\ ${ }^{10}$ Faculty of Health Sciences and Western's Bone and Joint Institute, University of Western \\ Ontario, London, Ontario, Canada. \\ ${ }^{11}$ Department of Rehabilitation Medicine, Maastricht University, Maastricht, Netherlands. \\ ${ }^{12}$ Department of General Practice, Erasmus MC, University Medical Center Rotterdam, \\ Rotterdam, Netherlands. \\ ${ }^{13}$ Center for Muscle and Joint Health, University of Southern Denmark, Odense, Denmark. \\ ${ }^{14}$ Center for Health and Medical Psychology, School of Law, Psychology, and Social Work, \\ Örebro University, Örebro, Sweden.
}

Chronic primary pain is defined as pain in at least one anatomical region that persists or recurs for $>3$ months and that is associated with substantial emotional distress or functional disability and that cannot be better explained by another chronic pain condition ${ }^{11}$. In patients with chronic back pain as a symptom of another disease - such as endometriosis, pancreatitis, aortic aneurysm, renal colic, inflammatory bowel disease or rheumatoid arthritis - it is coded under the new classification 'chronic secondary musculoskeletal pain'. The fourth edition of the Diagnostic and Statistical Manual of Mental Disorders (DSM-IV) included a pain-specific mental disorder, but this diagnosis was not retained in DSM- 5 owing to the uncertain importance of medically unexplained pain and the lack of clarity about what psychological factors are of relevance in explaining the symptoms, among other reasons ${ }^{12}$.

This Primer presents the current state of the art of the epidemiology, diagnostic triage, risk factors, prevention and management of low back pain. This Primer also reviews the current knowledge on the mechanisms of back pain, including genetic risk factors, neurobiology and cognitive, behavioural and emotional mechanisms.

\section{Epidemiology}

Low back pain is a substantial burden to patients and society (FIG. 1). Indeed, in the 2016 Global Burden of Disease Study, low back pain was the leading cause of years lived with disability (YLDs) and was in the top 10 causes of YLDs in all 188 assessed countries ${ }^{13}$. This high ranking is in large part due to the high prevalence of low back pain. In one systematic review of 165 studies from 54 countries, the mean point prevalence of low back pain in the general population was $\sim 18 \%$ and 1-month prevalence was $\sim 30 \%$. Lifetime prevalence was $\sim 40 \%$ and was particularly high in individuals $40-80$ years of age and in women, the latter of which have a $20 \%$ increased risk of low back pain compared with men ${ }^{14}$. Socio-economically disadvantaged groups are much more likely to report persistent pain and substantial interference with daily functioning than socio-economically advantaged counterparts ${ }^{15,16}$. The risk of developing recurrent low back pain within a year after the resolution of an episode of acute low back pain is estimated to be $\sim 25 \%{ }^{17}$.

Most of the epidemiological data on low back pain concern western countries in Europe, the United States and Australia, although the prevalence in other regions has been assessed in some studies. The highest point prevalence of low back pain has been reported in highincome countries (32.9\%), with lower rates in middleincome countries $(25.4 \%)$ and low-income countries $(16.7 \%)$ in some studies ${ }^{14}$. In one systematic review, the mean point prevalence of chronic low back pain in Latin America was estimated as $31.3 \%{ }^{18}$. Another systematic review demonstrated a point prevalence of $32 \%$ in adults and $12 \%$ in adolescents in Africa; the mean lifetime prevalence, on the basis of six studies, was $62 \%$ in adults and $35 \%$ in adolescents ${ }^{19}$. The authors conclude that the prevalence of low back pain in Africa is comparable to the prevalence figures in western jurisdictions ${ }^{19}$. Studies evaluating the epidemiology of low back pain in Asia are scarce but have suggested that low back pain is a health problem among economically productive age groups and is associated with functional limitations in daily life activities $^{20,21}$. In general, studies used different definitions of back pain, differences in duration, its onset and whether or not people sought health care for their back problems, which may have influenced the reported prevalence rates.

\section{Children, adolescents and elderly individuals}

Low back pain has been suggested to start early in childhood, continue into adulthood and persist in elderly individuals, at least in a part of the general population ${ }^{22}$, although valid cohort data to confirm or refute this hypothesis are not yet available. Studying the prevalence of low back pain in children and adolescents might allow intervention at an earlier stage in the development of low back pain in the future. On the basis of 10 studies, a meta-analysis estimated the mean point prevalence of low back pain as $12 \%$ in children and adolescents $<19$ years of age, with a mean lifetime prevalence, based on 30 studies, of $39.9 \%{ }^{23}$. The prevalence of low back pain in children increases with increasing age; for example, a prevalence of $1 \%$ and $6 \%$ has been reported in children 7 years and 10 years of age, respectively, with a prevalence of $18 \%$ in adolescents 14 years and 16 years of age ${ }^{24}$. On the basis of a review of 56 studies, lifetime prevalence reaches adult levels by 18 years of age ${ }^{25}$.

Regarding the elderly, one review showed that the peak prevalence of low back pain occurred in individuals between 40 and 69 years of age, after which the prevalence declines ${ }^{14}$. Similar results were obtained in another study if all types of low back pain were considered; however, if only more severe forms are included, the prevalence steadily increased in individuals $\geq 65$ years of age ${ }^{26}$. Whether the proportion of individuals with nonspecific low back pain differs between young and elderly individuals is unclear. However, the proportion 


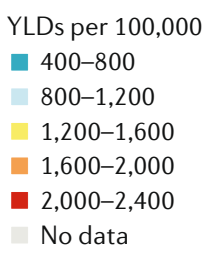

Fig. 1 | Years lived with disability for low back pain. Low back pain was one of the leading causes of years lived with disability (YLDs) in high-income, high-middle-income and middle-SDI (Socio-Demographic Index) quintile countries in 2016. Data from Global Burden of Disease Study, 2016 (REF. ${ }^{241}$ ).

of individuals with comorbidities is most likely higher in elderly individuals.

\section{Risk factors}

Back pain is a complex and multifactorial condition that likely develops as result of the interaction between several risk factors ${ }^{27}$. Given the high incidence of back pain, many individuals will experience an episode of acute low back pain at least once in their lifetime. However, some risk factors are associated with a higher occurrence of low back pain. Systematic reviews of risk factors for low back pain ${ }^{28}$ and sciatica ${ }^{29}$ have suggested that physical risk factors (such as prolonged standing and lifting heavy weights), an unhealthy lifestyle (such as smoking and obesity) and psychological factors (such as distress and the expectations that pain indicates bodily harm or injury) increase the risk of a back pain episode. In addition, manual tasks involving, for example, heavy loads, awkward postures and lifting objects not close to the body, as well as being distracted during an activity or task, were identified by patients as triggers of a new episode of sudden-onset acute low back pain ${ }^{30}$.

Genetic factors. The heritability of back pain has been estimated as $32-44 \%$ from twin studies ${ }^{31-33}$. Familial genetic mutations with a high penetrance that have a Mendelian mode of inheritance and that co-segregate with Modic changes (pathological changes to the vertebral endplate, which can be observed using MRI) have been identified in two families with a history of sciat$\mathrm{ica}^{34}$. In addition, other mutations that contribute to diseases affecting the spine and cause back pain, such as for spondylarthropathies, have been reported ${ }^{35,36}$. Most data on the role of genetics in back pain have come from genetic association studies, which identified common polymorphisms with modest effect sizes; of these studies, genome-wide association studies (GWAS) are the gold standard and enable the estimation of the heritability of a trait that is attributable only to common genetic variants. On the basis of these studies, the heritability of back pain based on common genetic variants has been estimated as $\sim 7 \%^{37}$. However, only one back-pain-related GWAS meta-analysis on lumbar disc generation has been published to date, in which none of the cohorts had been studied in a previous meta-analysis ${ }^{38,39}$. All other studies used a candidate gene approach in which pre-specified variants were studied on the basis of evidence-based assumptions of their involvement in the disease pathophysiology. Additional GWAS of back pain might provide new and reliable data on the genetic contribution to this condition, and current efforts are also currently underway to try to identify genetic variants associated with risk of acute episodes of back pain becoming chronic.

One review of genetic association studies on back pain revealed 47 studies that reported an association between 120 unique genetic variants (across 43 loci) and back-pain-related phenotypes (BOX 1). Of these genetic variants, 64 have been tested for association with various pain phenotypes (including low back pain) that were present for at least 3 months in a separate study, and 11 were replicated, reinforcing the role of some of these genes in the pathophysiology of chronic pain conditions, including back pain ${ }^{40}$. Despite the identification of these risk variants, only the mechanisms underlying 


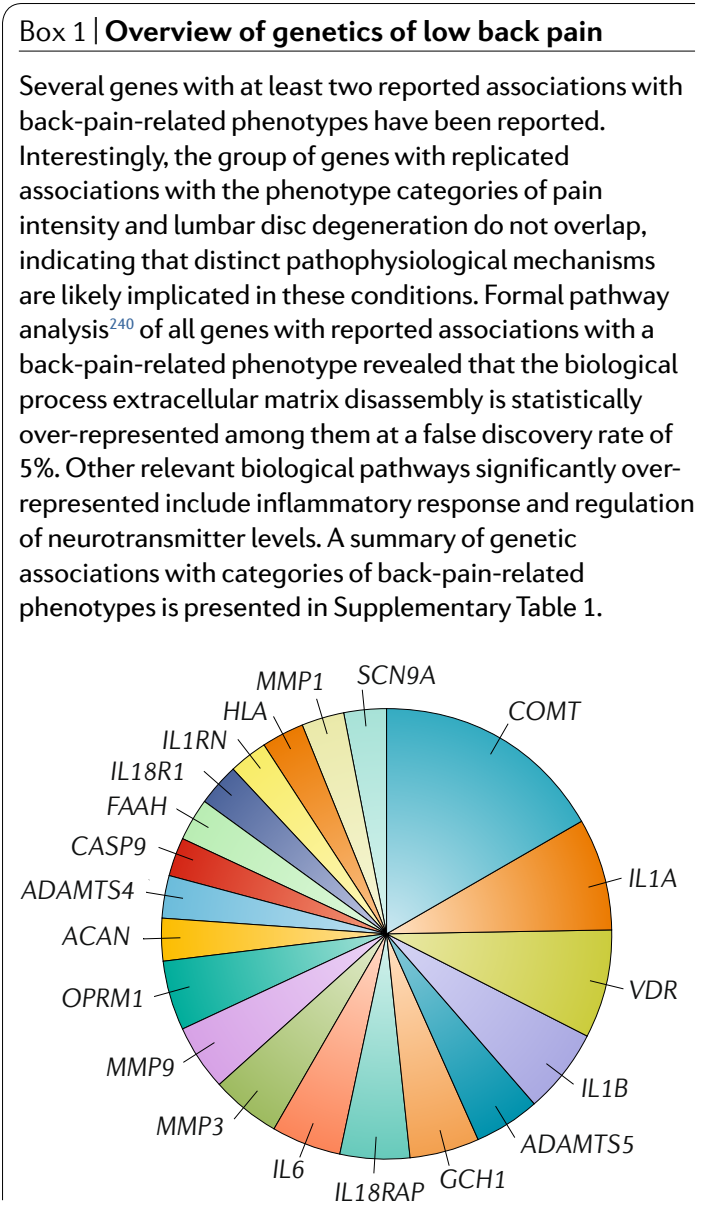

the contribution of GCH1 $\left(\mathrm{REF}^{41}\right)$ and $\mathrm{COMT}^{42,43}$ to several pain states, not exclusively back pain, have been investigated. GCH1 encodes GTP cyclohydrolase 1 $(\mathrm{GCH} 1)$, a rate-limiting enzyme for the synthesis of tetrahydrobiopterin (an essential cofactor for catecholamine, serotonin and nitric oxide production) that is increased in peripheral neuropathic and inflammatory pain states owing to enhanced GCH1 enzyme activity ${ }^{41}$. COMT encodes catecholamine- $O$-methyltransferase (COMT), which methylates and consequently deactivates catechol-containing substrates, such as adrenaline, noradrenaline and dopamine, and COMT variants that convey low enzyme activity contribute to increased pain via $\beta_{2}$-adrenergic and $\beta_{3}$-adrenergic receptors ${ }^{42-44}$. Importantly, the majority of genetic associations with back pain have not been replicated, and the use of these variants to improve diagnosis and treatment of back pain remains to be ascertained and requires further study. In addition, as pain conditions share genetic pathways of vulnerability, variants that contribute to the diagnosis and treatment of back pain are most likely not specific and may, in fact, contribute to the diagnosis and treatment of other pain conditions ${ }^{40}$.

\section{Mechanisms/pathophysiology}

The pathology underlying low back pain remains unknown in most cases, including individuals seeking medical care for acute or recurrent pain or chronic symptoms. Identifying the cause of back pain in these individuals has been an elusive goal. As back pain is a symptom, the aetiology could be influenced by numerous factors, including local and systemic factors, such as structural failure of the musculoskeletal tissues; inflammatory and immunological responses; genetic predisposition; excessive static or dynamic loading; emotional state; behavioural and environmental factors; beliefs and expectations about what might happen with back pain in the future and whether it can be controlled; the social consequences following the expression of pain (increased empathy or rejection); and social systems ${ }^{45,46}$. An individual's specific and variable response to a musculoskeletal insult might be a key determining factor for back pain.

\section{The simplistic injury model of back pain}

Despite the absence of a discernible illness or pathology in most individuals with low back pain, an injury model has long been used to explain this type of pain, particularly when pain occurs in the workplace. For many years, low back pain was considered a consequence of over-exertion or trauma from physically demanding activities, such as handling of heavy materials leading to damage or degeneration of the vertebrae, intervertebral discs or spinal muscles. However, this explanation is overly simplistic, particularly owing to the modest association of heavy physical demands with structural degenerative changes of these structures and pathophysiology ${ }^{46}$. Several other lines of research have forced a re-evaluation of this 'injury' approach to low back pain. First, many episodes of acute low back pain do not fit within a physical injury model; in a study of 1,172 patients with acute low back pain, one-third could not recall a trigger for the episode ${ }^{30}$. In addition, exposure to non-painful bodily triggers (such as being fatigued) or cognitive triggers (such as being distracted) was as hazardous as exposure to physical triggers (such as lifting weights), and exposure to both physical and nonphysical triggers was associated with a higher risk of back pain than exposure to only one factor ${ }^{47}$. Second, in cohort studies assessing the exposure to long-term suspected risk factors for back pain, job dissatisfaction and emotional distress were predictive of new back pain claims but not the physical aspects of work (such as spinal load) or the physical capacities of the worker (such as back muscle strength $)^{48}$. These data do not support a physical injury model of back pain.

\section{Potential local contributors to low back pain}

Although most patients with back pain lack a clear, identifiable pathology responsible for their symptoms, a fairly small portion of patients $(<5 \%)$ have traumatic or osteoporotic fractures that may contribute to back pain development or persistence. Although rare $(\sim 1 \%$ of cases), back pain can also result from conditions such as neoplasia, infection and inflammatory arthritis that directly affect the spinal structures. Pain also can be referred to the low back from many visceral conditions, including diseases of pelvic organs, such as prostatitis, endometriosis, renal disease (such as kidney stones), gastrointestinal disease and aortic aneurism, among other conditions, which have been estimated to account for 2\% of patients seeking primary care for low back pain. 

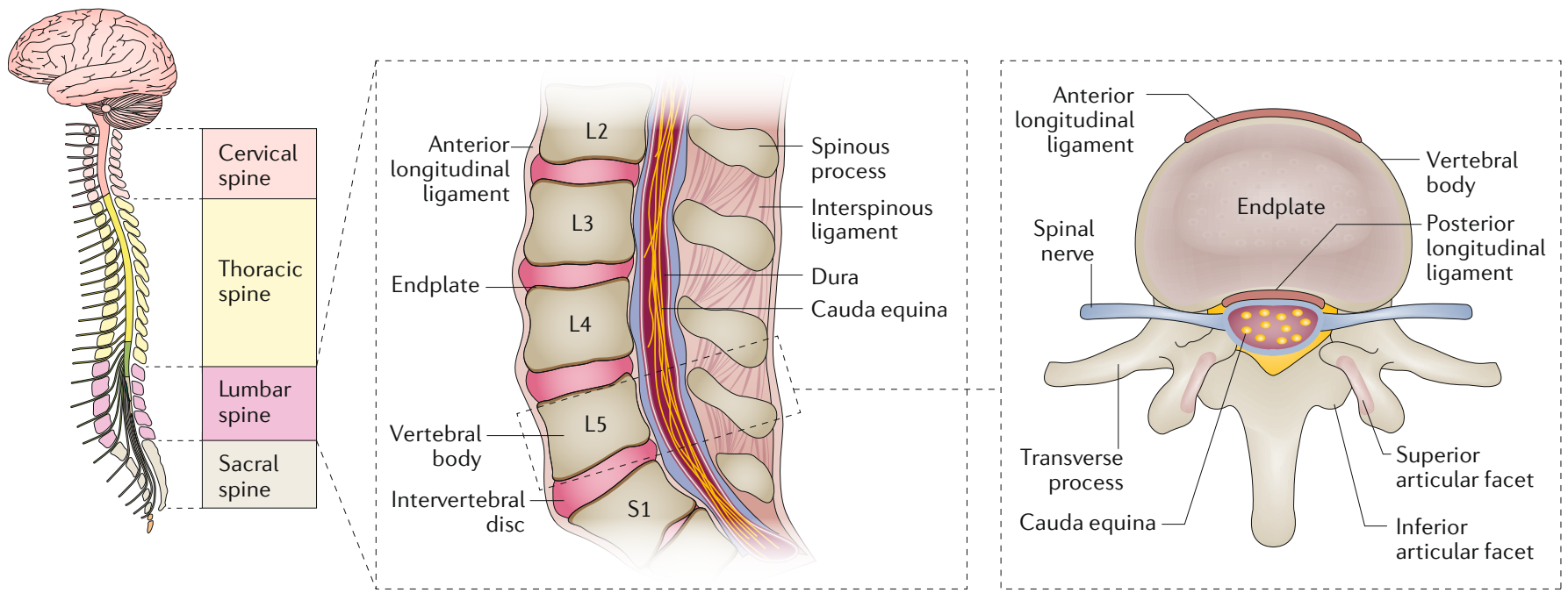

Fig. 2 | Vertebral anatomy. Although most patients with low back pain lack a discernible pathology that accounts for the pain, in extremely rare cases, damage to several structures within the vertebral column, including the facet joint, intervertebral disc, endplate or spinal nerves, can lead to back pain. Damage to these structures includes traumatic injury, inflammation or infection.

However, the main focus of this section is on lumbar spine contributors to low back pain.

Most structures of the lumbar region can contribute to low back pain if they are biochemically altered (for example, through inflammation) or damaged through degeneration or trauma (FIG. 2). Many spinal structures have sensory innervation, such as muscles, tendons, ligaments, fascia, facet joints, vertebrae, the outer annulus of the intervertebral disc, vascular tissue, the dura, nerve roots and dorsal root ganglia; however, the specific structures involved in common low back pain remain speculative.

Despite most of the intervertebral disc lacking sensory innervation, this structure has received the most attention as a nociceptive contributor of back pain, particularly with regards to disc degeneration. Indeed, the detection of disc degeneration by neuroimaging, often defined as a loss of signal intensity on T2-weighted MRI and disc narrowing, protrusion and extrusion, is modestly associated with back pain ${ }^{49,50}$. Defects or lesions of the endplate beyond Schmorl's nodes (that is, protrusions of the nucleus pulposus of the intervertebral disc through the endplate into the vertebral body), such as erosion lesions, corner defects or calcification, have also received increasing attention. Although the aetiology of these endplate defects or lesions is poorly understood, variation in their character, distribution and prevalence suggests different aetiologies (for example, developmental, degenerative or traumatic) and that they represent different pathological processes ${ }^{51}$ with different implications for pain ${ }^{52}$.

In addition, Modic changes that affect the endplate, adjacent vertebral body and bone marrow have been evaluated as possible sources of back pain (FIG. 3). Three types of Modic changes can be detected via signal variations with different MRI sequences. Type 1 changes, which are associated with back pain ${ }^{45}$, are speculated to represent bone oedema, inflammation and fibrovascular granulation tissue ${ }^{53}$, whereas type 2 changes represent fatty degeneration of the bone marrow and type 3 changes represent endplate sclerosis. Type 1 Modic changes have been attributed to physical trauma of the endplate, the localized action of inflammatory mediators, such as IL-1, and low-grade bacterial infection, with particular interest in Cutibacterium acnes (also known as Propionibacterium acnes) infection ${ }^{54}$. Endplate disruption might be key for the development of Modic changes $^{55,56}$. Recently, the molecular and cellular features of bone marrow affected by Modic changes (type 1 and 2) and adjacent discs were compared with unaffected spinal levels in individuals undergoing multi-level spinal fusion for degenerative conditions. The results provided evidence of fibrogenic and pro-inflammatory crosstalk between bone marrow and adjacent discs at spinal levels affected by Modic changes, which may relate to pathogenesis and have implications for low back pain ${ }^{57}$. In particular, large endplate lesions or defects and type 1 Modic changes have been found more frequently in individuals reporting back pain and seeking health care than Modic changes of any type (including type 2 ) $^{49,52}$. However, endplate defects and Modic changes are also present in individuals without back pain and, therefore, are of little use in differentiating those with or without back pain. Such findings by themselves might not be sufficient to cause back pain of such severity as to warrant reporting or seeking health care. Moreover, degenerative changes of spinal structures, including bone, endplates, discs, paraspinal muscle and vessels, develop together ${ }^{58}$, making it challenging to identify specific findings or combinations of findings that might be more important contributors to back pain.

Other potential contributors to back pain are the facet joints, also called the zygapophyseal joints, spinal muscles and nerves. The facet joints are articulations of the posterior arch of the vertebrae and are innervated by the medial branches of the dorsal rami of the spinal nerve $\mathrm{e}^{59}$. In terms of spinal muscles, low back pain 


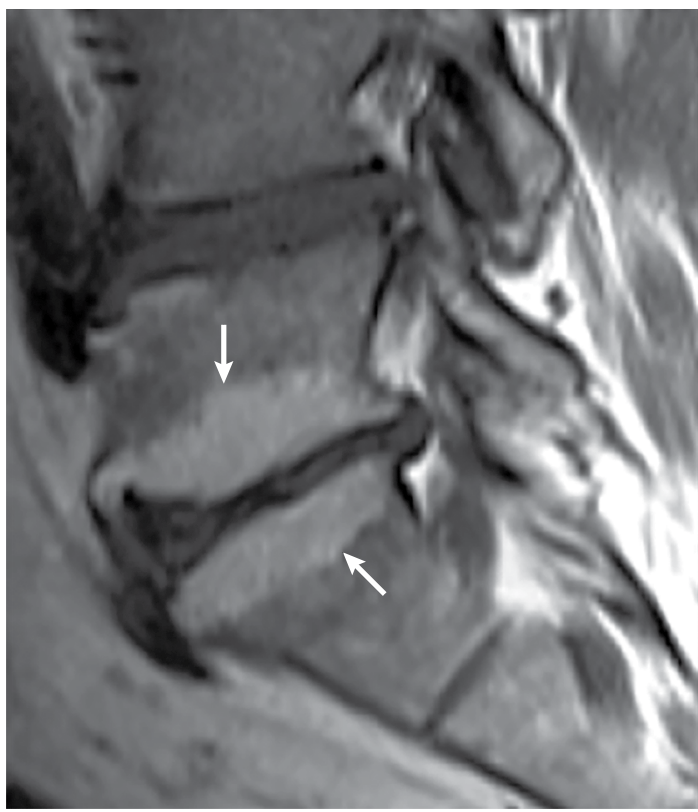

Fig. 3 | Type 1 Modic changes. Type 1 Modic changes (arrows) correspond to bone oedema or inflammation and fibrovascular granulation tissue and can be observed in some patients with low back pain. However, these changes can be observed in asymptomatic individuals and, therefore, have been of little use to date in differentiating those with or without back pain. Adapted from REF. ${ }^{242}$, CC-BY-4.0.

has been associated with smaller multifidus muscles, but the association with other paraspinal muscles is less clear, as is the association with muscle composition (for example, fatty infiltration). In an investigation specifically of dynamic trunk exercise to fatigue, there was no association found between resultant back pain intensity and spinal muscle damage, as indicated by increased intensity on T2-weighted MRI. Another study on exercise-induced pain suggested that initial reports of pain after intensive exercise were more strongly influenced by fear of pain, whereas the inflammatory process and pain sensitivity played a larger role for later pain intensity reports ${ }^{60,61}$. In some individuals, pain typically radiates into the leg below the knee (such as in sciatica); in these individuals, the radiation pattern provides an indication of the involved segmental level. The pathophysiology of radicular pain is not fully understood but might be related to lesions that affect dorsal root ganglia or indirectly affect spinal nerves and nerve roots by ischaemia or inflammation of the axons within the nerve $^{62}$. The spreading of the radicular afferent signal is a complex phenomenon, possibly with the involvement of the inflammatory cascade. Generally, most structures in the lumbar spine can be a potential source of pain, but reliable tests to identify the specific structure implicated for a given patient are lacking, as well as effective treatments specific for each structure.

\section{MRI findings in asymptomatic individuals}

The modest association of pain with the degree of musculoskeletal degenerative and pathological findings observed using imaging is not unique to back pain; the presence and degree of peripheral joint pain is also not highly correlated with the extent of imaging findings of osteoarthritis. However, stronger associations have been observed in large, highly controlled studies of discordant knee pain and osteoarthritis within individuals, suggesting that substantial confounding and diluting of associations between relevant degenerative changes and pain reporting might be occurring. These findings challenge researchers to devise studies that more adequately adjust for confounding factors and to examine modifiers of the relationship between structural changes and other findings of interest and pain. Identifying anatomical and pathophysiological differences between individuals with and those without back pain who have similar extents of disc degeneration or other findings of interest on imaging might identify key factors of the pathology, modifiers and mechanisms of low back pain $^{63}$. In particular, inflammatory and immunological responses may be informative. It should also be kept in mind that disc, endplate, vertebral and other structural changes observed from imaging might contribute to low back pain, or alternatively might be markers of other conditions that lead to back pain.

\section{Brain mechanisms}

Brain imaging studies have begun to examine changes in brain structure and function that are related to back pain $^{64}$. Structural changes in grey matter have, for instance, been reported in the dorsolateral prefrontal cortex $^{65-67}$, thalamus, temporal lobes, insula and the primary somatosensory cortex in individuals with chronic back pain compared with healthy controls. Alterations in brain function have been investigated at rest and following peripheral stimulation. Changes in resting state activity and functional connectivity in patients with back pain compared with healthy controls have been observed in several brain regions, including the medial prefrontal cortex (mPFC), cingulate cortex, amygdala and insula ${ }^{68,69}$. Following peripheral stimulation, patients with chronic back pain had increased activation of painrelated brain regions such as the primary and secondary somatosensory cortex and insula ${ }^{70}$ and reduced activity $^{70}$ and functional connectivity ${ }^{71}$ of the periaqueductal grey, which is known to contribute to the top-down modulation of pain (FIG. 4).

The transition from an acute back pain state to chronic back pain might involve changes in the functional connectivity between the PFC and regions of the limbic system. Indeed, this was suggested in one longitudinal study that monitored individuals with subacute back pain for 1 year, after which back pain was persistent in some participants ${ }^{68}$. In this study, participants with persistent pain showed an increased functional connectivity between the mPFC and the nucleus accumbens (NAc) at the initial assessment, compared with individuals who did not develop chronic pain ${ }^{68}$, and structural and functional connectivity between the mPFC, amygdala and NAc was still different between groups after 3 years $^{72}$. The consistent finding of smaller amygdala and hippocampus volumes over a period of several years in those who progressed to chronic pain suggests that these structural alterations might have existed before pain onset and, therefore, potentially predisposed 
individuals to the development of chronic pain ${ }^{72}$. Other studies on back pain have demonstrated alterations in similar brain structures involved in cognitiveaffective processing (such as the hippocampus and striatum $)^{73-76}$, and when compared with meta-analytic brain maps, the brain signature of chronic back pain more closely resembles that of emotion processing than that of acute pain ${ }^{77}$. Additional functional changes in individuals with chronic back pain include reduced network efficiency ${ }^{78}$ and whole-brain reorganization of functional connectivity ${ }^{79,80}$, compared with healthy controls. Together, these findings advocate a perspective on chronic back pain that comprises structural and functional alterations in a dynamic network of interacting brain regions and that acknowledges the pivotal role of regions involved in pain-related processes beyond nociception in driving the development of chronic pain.

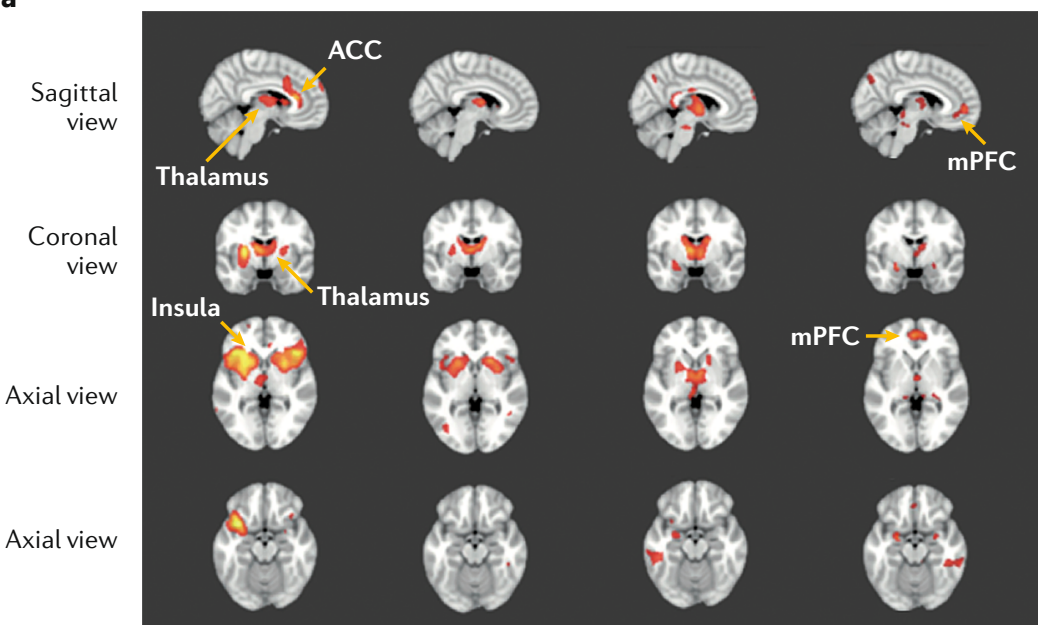

b

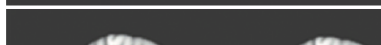

$\underset{\text { Siew }}{\text { Sagittal }}$ view

Coronal view

Axial view

Axial view
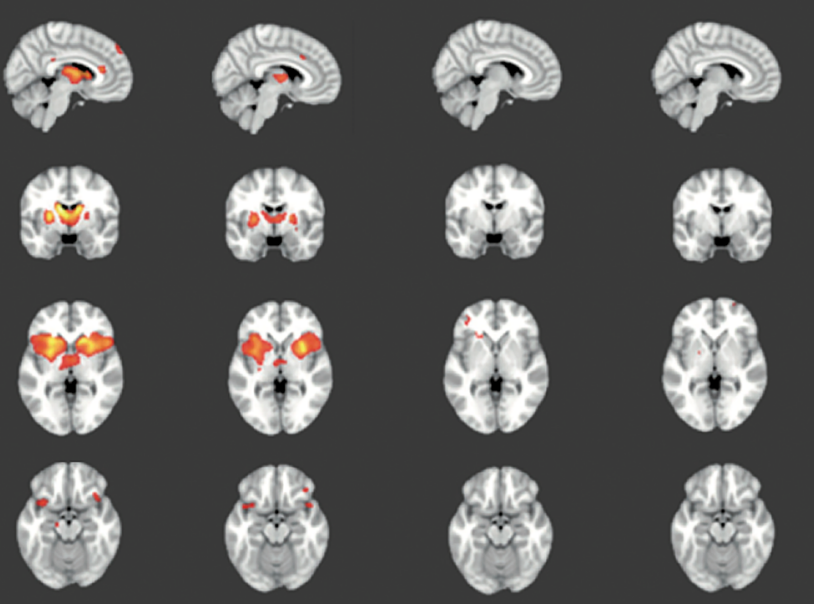

Fig. 4 | Changes in brain activity underlying the transition from acute to chronic back pain. Brain scans using functional MRI during early visits (12 weeks and 19 weeks) past pain onset show activation in brain regions commonly engaged during acute pain (such as the thalamus, anterior cingulate cortex (ACC) and insula). After 1 year, significant activation differences among those who developed chronic pain (panel a) and those who did not (panel b) were found in the medial prefrontal cortex (mPFC) more closely linked to self-referential and emotional processing in the amygdala. Activation clusters are shown using a colour scale ranging from red (lower activation) to yellow (higher activation). The time points refer to the average duration past pain onset. Adapted with permission from REF. ${ }^{77}$, Oxford University Press.

\section{Cognition, emotion and behaviour}

Pain is a motivational state that initiates early defensive and late recuperative behaviours, which primarily function to promote recovery from injury ${ }^{81}$. Predictions or expectations of the occurrence, magnitude and consequences of pain are generated on the basis of prior information about the state of the body (such as 'this activity is likely to harm my back'). These predictions are influenced by a generative model of an individual's own body (such as 'my back is vulnerable') and other metacognitions about health and illness (such as 'there is nothing I can do to change my pain' and 'pain is always a sign of harm'). Predictions or expectations of pain can also be generated by an individual's own experiences, in addition to verbal information and observations of what happens to other people in similar contexts ${ }^{82}$. From a Bayesian perspective, expectations of pain are compared with the actual sensation, which can confirm the prediction and the beliefs (a match) or, alternatively, lead to a prediction error that urges the individual to update these beliefs (a mismatch) ${ }^{83,84}$. An individual's homeostatic goal is to minimize prediction errors and to increase the accuracy of predictions (FIG. 5). Whether the prediction is corrected or not largely depends on the relative precision of the sensory input and the expectation of pain ${ }^{84-86}$. If the sensory input is less precise, the perception will be more in line with the prior expectations and vice versa. Given the ambiguity and imprecise nature of low back pain, expectations can strongly influence the perception of pain, such that the expectation of back pain might be enough to increase its intensity or perceive inoccuous sensations as painful ${ }^{87,88}$.

In patients with back pain, misinterpretations of pain as a sign of physical harm ${ }^{89}$ usually lead to painrelated fear and avoidance behaviours that further fuel the disability, depression and anxiety ${ }^{90-93}$. Indeed, one meta-analysis demonstrated a moderate to large average sample size-weighted correlation coefficient of 0.42 (with a range of 0.33-0.45) for pain-related fear and disability in individuals with acute or chronic pain ${ }^{94}$. Individuals reporting fear-avoidance beliefs had poorer work-related outcomes with subacute low back pain (that is, individuals with low back pain for between 4 weeks and 3 months), with odds ratios ranging from 1.05 to 4.64 in four cohort studies ${ }^{95}$. By contrast, fearful beliefs in more-acute low back pain (with duration of $<2$ weeks) and chronic low back pain (duration of $>3$ months) did not predict return to work ${ }^{95}$. These results suggest that modifying negative expectations regarding return to work might avoid delayed recovery and the development of chronic pain in individuals with low back pain during the subacute phase. In addition, one systematic review and meta-analysis demonstrated self-efficacy, psychological distress and pain-related fear as significant mediators of the effect of pain on disability ${ }^{96}$.

The prediction of pain can be influenced by classical (Pavlovian) conditioning, which is the association of pain with neutral cues that precede the occurrence of pain. These cues can be non-painful tactile, visceral or proprioceptive sensations that activate the pain memory. As a result, these conditioned stimuli elicit defensive avoidance behaviour, which is adaptive in the 
acute phase $^{97}$. However, excessive reliance on defensive behaviours can paradoxically maintain or increase painrelated fear ${ }^{98}$ and, therefore, compromise daily activities, interfere with work and social participation and lead to negative affect ${ }^{99}$. For example, avoidance behaviour precludes the possibility to test whether the triggers are still predicting pain or harm, thereby maintaining fear ${ }^{100-102}$. In addition, generalization can occur, during which perceptual or conceptual variations of the original stimulus also elicit avoidance behaviour. One study demonstrated that patients with chronic musculoskeletal pain more strongly generalize their pain expectancies from a painful movement to movements that were never associated with pain than healthy controls ${ }^{103}$. That is, patients may insufficiently discriminate between stimuli or situations that are safe from those that are painful. In addition, preliminary evidence suggests that hyperalgesia (the same stimulus eliciting a higher pain response than usual) and allodynia (a non-nociceptive stimulus eliciting a pain response) can be considered learned (conditioned) responses ${ }^{88,104}$, explaining why the cortical representation of non-nociceptive stimuli is disrupted in people with chronic pain. For example, people with chronic back pain may have lower proprioceptive acuity, with disruptions in the perceived size and alignment of body parts ${ }^{105}$.

Pain and avoidance behaviour can also be maintained by operant conditioning (law of effect), in which the valence of behavioural outcomes influences the likelihood that this behaviour will be maintained ${ }^{106,107}$. For example, when individuals do something to avoid or reduce their pain, which has a beneficial effect on pain, they keep repeating it. Psychological treatments, and cognitive-behavioural therapy in particular, aim to challenge patients' beliefs and pain-outcome expectancies and encourage them to sample their interoceptive environment differently (see Management) ${ }^{108}$.

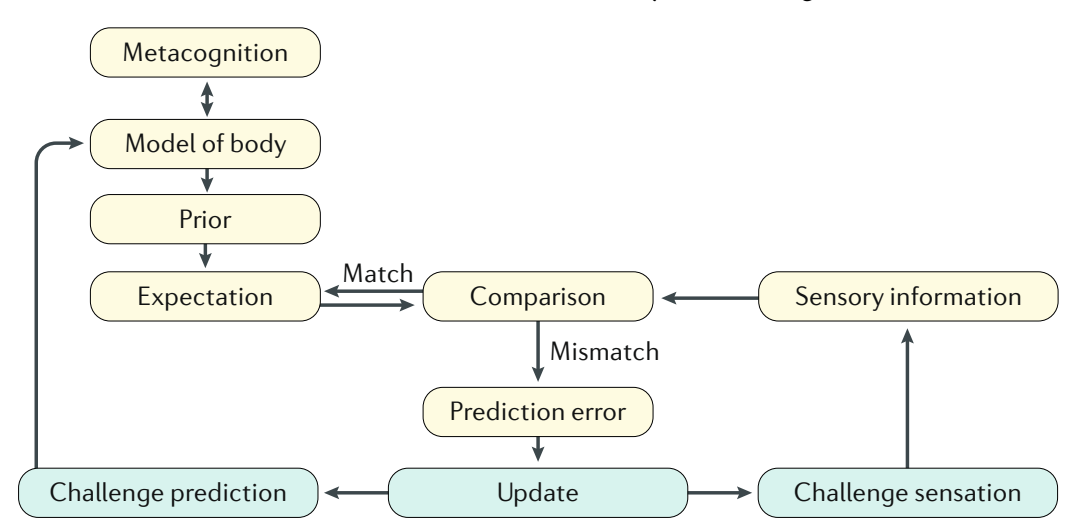

Fig. 5 | How expectations shape back pain. Expectations (such as 'this event will cause pain') are derived from an idiosyncratic and generative model of the body in pain with hierarchically structured beliefs. Metacognitions are high-level beliefs that include the possibility of control (such as 'there is nothing I can do to relieve pain'), whereas a prior is a lower-level belief about a state of the body (such as 'lifting objects increases the pain'). Expectations about upcoming sensations are compared with incoming sensory information (not restricted to nociception), and the difference between the expectation and the sensory input is called the prediction error. The individual's homeostatic goal is to minimize prediction errors through at least two updating possibilities: confirming the expectation (the person feels what she/he expects; 'match') or learning ('mismatch'). In the latter, updating the prediction is challenged and replaced by an adapted one (the person learns that it is different than expected). Learning may create more accurate predictions and a more valid generative model of the body.

\section{Diagnosis, screening and prevention Classification of low back pain}

Clinical practice guidelines recommend a diagnostic triage approach in which patients with low back pain are classified into one of four broad categories: those with a visceral disorder (for example, patients with kidney stones), a specific spinal disease (such as axial spondyloarthritis), radicular syndromes or nonspecific low back pain ${ }^{109}$. In primary care, the majority of patients have nonspecific low back pain (typically $90 \%$ of patients) ${ }^{110,111}$ and, when pain persists for $>3$ months, many of these patients will fit the ICD-11 criteria for chronic primary pain ${ }^{11}$. Typically, $<1 \%$ of back pain presentations to primary care are caused by visceral or spinal diseases ${ }^{112,113}$. Identifying these disorders is important as they are managed differently from nonspecific low back pain or radicular syndromes.

\section{Diagnostic work-up}

A clinical assessment is used to identify patients with suspected specific spinal disease or visceral disorders who require further diagnostic work-up. Both nonspecific low back pain and radicular syndromes do not require further initial diagnostic work-up, as their initial management is the same as for both disorders. However, if a patient does not respond to a therapy trial and is a candidate for surgery, imaging (for example, using MRI) is indicated to identify an abnormality that could be addressed by surgery.

Diagnostic work-up during the initial clinical assessment is warranted only in individuals with suspected spinal pathology or visceral disease. Red flags, such as unexplained weight loss, have traditionally been used to identify patients with a higher probability of these conditions (TABLE 1); however, few red flags have high diagnostic accuracy ${ }^{110}$. For example, some guidelines for the management of back pain endorse the use of the 'thoracic pain' red flag to screen for cancer, but the presence of thoracic pain has both a positive and a negative likelihood ratio of 1.0, which is not informative (the sign is equally common in those with and those without cancer $)^{114}$. The most common problem with red flags is false positives; $80 \%$ of patients presenting to primary care have at least one red flag, although $<1 \%$ of patients have a specific spinal pathology ${ }^{111}$. Given this discrepancy, a more useful approach when deciding which patients require further diagnostic work-up is to rely upon the smaller subset of red flags with promising diagnostic accuracy and consider a combination of red flags in the context of a full clinical assessment ${ }^{115}$. In addition to the red flags, other flags have been assigned to different kinds of prognostic factors, including orange (psychiatric symptoms), yellow (cognitive, emotional and behavioural), blue (work-related) and black (system-related) flags ${ }^{116}$ (TABLE 1).

To identify patients who require further diagnostic work-up, some guidelines take into account the consequences of a missed diagnosis and the certainty of the diagnosis; for example, the imaging guidelines for the American College of Physicians recommend deferring diagnostic work-up pending a trial of therapy in patients with a low suspicion of cancer but suggest immediate 


\begin{tabular}{|c|c|c|}
\hline Flag & Nature & Examples \\
\hline Red & $\begin{array}{l}\text { Alerting features that when } \\
\text { present raise suspicion of } \\
\text { serious pathology }\end{array}$ & $\begin{array}{l}\text { - New bladder or bowel dysfunction (possible cauda equina syndrome) } \\
\text { - Intravenous drug use, fever or recent infection (possible spinal infection) } \\
\text { - Previous history of cancer (possible vertebral metastases) }\end{array}$ \\
\hline Orange & Psychiatric symptoms & $\begin{array}{l}\text { - Clinical depression } \\
\text { - Personality disorder }\end{array}$ \\
\hline \multirow[t]{3}{*}{ Yellow } & $\begin{array}{l}\text { Beliefs, appraisals and } \\
\text { judgements }\end{array}$ & $\begin{array}{l}\text { - Unhelpful beliefs about pain: indication of injury as uncontrollable or } \\
\text { likely to worsen } \\
\text { - Expectations of poor treatment outcome } \\
\text { - Delayed return to work }\end{array}$ \\
\hline & Emotional responses & $\begin{array}{l}\text { - Distress not meeting criteria for diagnosis of mental disorder } \\
\text { - Worry } \\
\text { - Fears } \\
\text { - Anxiety }\end{array}$ \\
\hline & $\begin{array}{l}\text { Pain behaviour (including pain } \\
\text { coping strategies) }\end{array}$ & $\begin{array}{l}\text {-Avoidance of activities due to expectations of pain and possible re-injury } \\
\text { - Over-reliance on passive treatments, such as hot packs, cold packs and } \\
\text { analgesics }\end{array}$ \\
\hline Blue & $\begin{array}{l}\text { Perceptions about the } \\
\text { relationship between work } \\
\text { and health }\end{array}$ & $\begin{array}{l}\text { - Belief that work is too onerous and likely to cause further injury } \\
\text { - Belief that workplace supervisor and workmates are unsupportive }\end{array}$ \\
\hline Black & System or contextual obstacles & $\begin{array}{l}\text { - Legislation restricting options for return to work } \\
\text { - Conflict with insurance staff over injury claim } \\
\text { - Overly solicitous family and health-care providers } \\
\text { - Heavy work, with little opportunity to modify duties }\end{array}$ \\
\hline \multicolumn{3}{|c|}{$\begin{array}{l}\text { Flags refer to potential risk factors for the development of persistent pain and associated disability: these are suspicion of serious } \\
\text { biological pathology (red flags); psychiatric symptoms that probably require specialist mental health referral (orange flags); } \\
\text { psychological risk factors, such as fears and unhelpful beliefs (yellow flags); workers' perceptions that their workplace is stressful, } \\
\text { unsupportive and excessively demanding (blue flags); and observable characteristics of the workplace and nature of the work as } \\
\text { well the insurance and compensation system under which workplace injuries are managed (black flags). Adapted with permission } \\
\text { from REF. }{ }^{116} \text {, Oxford University Press. }\end{array}$} \\
\hline
\end{tabular}

further diagnostic work-up of individuals with suspected cauda equina syndrome (whereby compression of the nerve roots of the cauda equina causes loss of motor and sensory function) and infection (such as epidural abscess) owing to the adverse consequences of delayed diagnosis $^{117}$. The precise diagnostic work-up depends on the suspected underlying disorder. Patients with suspected vertebral compression fracture require imaging of the vertebral column to confirm or exclude the diagnosis. Referral to a rheumatologist is indicated in those with a strong suspicion of axial spondyloarthritis, whereas referral can be delayed in those with lower suspicion until more scientific evidence becomes available.

\section{Screening for risk of chronic pain}

Although many patients who seek care for an episode of acute low back pain improve, $\sim 10-15 \%$ of patients develop chronic pain and disability ${ }^{115,118,119}$. Owing to the considerable suffering and cost associated with chronic pain, preventing its development is essential ${ }^{120-122}$. However, identifying these patients at early stages is challenging.

Screening tools have been developed to help clinicians assess the risk of a patient seeking care for acute pain developing chronic pain and its related disability, such as the Örebro Musculoskeletal Pain Screening Questionnaire (ÖMPSQ) ${ }^{123}$ and the STarTBack tool ${ }^{124}$. These tools assess psychological and social factors and include questions about duration of pain, emotional distress, fear-avoidance beliefs, self-perceived functioning and expected return to work, which are associated with the development of chronic-pain-associated disability ${ }^{121,125}$. Both tools have been validated in the clinic, and the ÖMPSQ can predict the risk of future work absenteeism due to pain ${ }^{126}$ but can less accurately predict pain outcomes, whereas STarTBack predicts future function but is less accurate in predicting work disability and pain outcomes. The short version of these screening tools requires little time to undertake and can reliably stratify individuals into low, medium and high risk of pain-related disability ${ }^{126}$. Although these screening tools are not perfect, and research is focusing on improving them, they are nevertheless adequate for classifying patients in clinical settings ${ }^{127}$. Preferably, the patient completes the screening tool during their first clinical visit to estimate their risk. In addition, these screening tools might also be useful in isolating the most potent risk factors for chronic-pain-associated disability. Indeed, the ÖMPSQ has been successfully used to identify highrisk cases and then to provide an intervention aimed at the elevated risk factors for these workers ${ }^{127,128}$. Patients with a higher risk of chronic-pain-associated disability will likely need a more-thorough assessment before starting treatment to ensure that the proper targets have been identified.

\section{Primary prevention}

Many popular prevention interventions for low back pain are still based on the view that low back pain is a physical injury ${ }^{129}$. Accordingly, ergonomic approaches are used to control excessive strain, protect the spine and prevent injury, including safe lifting guidelines, workplace redesign and ergonomic furniture. However, despite the popularity of these approaches, and although 


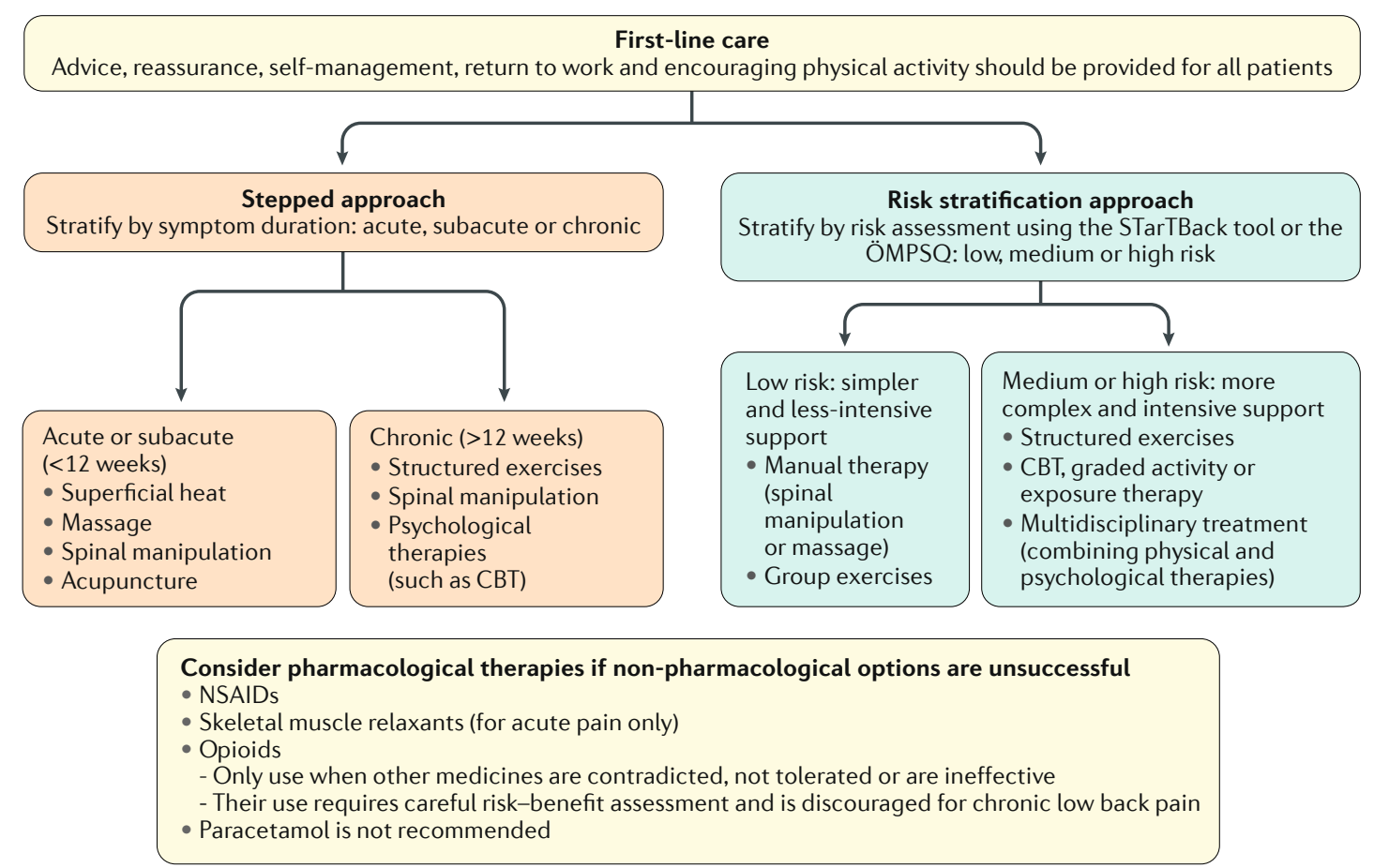

Fig. 6 | Management of low back pain. The management of low back pain can include two common approaches. The traditional stepped-care approach entails stratifying patients according to the duration of symptoms, followed by initially simple care with progression to more complex care if initial treatments are ineffective. A more recent approach is to use validated risk stratification tools, such as the STarTBack Screening Tool or the Örebro Musculoskeletal Pain Screening Questionnaire (ÖMPSQ), to stratify patients on the basis of their risk of chronic-pain-related disability into different care pathways. Following stratification, treatment is then matched to the patient's risk level. Pharmacological therapies are considered only if non-pharmacological options are unsuccessful. CBT, cognitive-behavioural therapy. Reproduced with permission from Almeida M, Saragiotto B, Richards B \& Maher CG. Primary care management of nonspecific low back pain: key messages from recent clinical guidelines. Med. J. Aust. 2018; 208 (6): 272-275. ๑ Copyright 2018 The Medical Journal of Australia.

some are mandatory workplace regulations, few trials have investigated the efficacy of these strategies. One of the most well-known is a randomized controlled trial (RCT) involving 2,534 US postal workers that demonstrated no reduction in the incidence of work-related low back pain with education in safe work practices and ergonomic redesign of the workplace ${ }^{130}$. Although this result was surprising at the time of publication of this study, the current understanding of the diverse risk factors for low back pain suggest that the one-dimensional prevention approach used in this trial could be insufficient ${ }^{130}$.

A systematic review of prevention interventions composed of 21 RCTs and 30,850 individuals demonstrated that common strategies such as back supports, shoe insoles and education for avoiding back injuries lacked evidence that they do prevent low back pain ${ }^{131}$. The only effective intervention in this study was exercise, or exercise in combination with education, the latter of which reduced the risk of an episode of low back pain by $45 \%$. These exercises were not confined to the spine but aimed to improve aerobic fitness, strength, flexibility and skill or coordination. Although physical exercise can have a large preventive effect on low back pain, it requires considerable commitment from participants ${ }^{131,132}$. Indeed, one trial that demonstrated a $50 \%$ reduction in work absenteeism due to back pain required participants to attend 20 exercise sessions over 3 months (which is consistent with recognized guidelines for exercise prescription $)^{133}$. Whether the effects of exercise on back pain prevention are a result of the improved physical capacity to tolerate stress on the spine or the improved relationships with co-workers and employer and job satisfaction is unknown.

\section{Management}

Clinical practice guidelines encourage clinicians to adopt a biopsychosocial perspective for the management of low back pain ${ }^{109}$. Patients are taught to self-manage their condition, and clinicians are encouraged to adopt a stepped approach to care to avoid unnecessary or overcomplicated treatment (FIG. 6). To this end, back pain management should be started in a primary care setting rather than in a specialist setting. Nonspecific low back pain is not a medical emergency; thus, it should not be managed in the hospital emergency department ${ }^{134}$. A treatment option for individuals with low back pain is a risk stratification approach, which aims to limit progression to chronic back pain. This approach involves a risk-targeted treatment strategy, whereby individuals of high risk receive targeted treatments to prevent the development of chronic pain and individuals at low risk receive lessintensive therapies. In individuals with chronic back pain and interference with daily life ( $>3$ months), management preferably takes place in a multidisciplinary setting. 


\section{Risk stratification approach}

Secondary prevention aims to prevent the development of chronic-pain-associated disability in individuals at high risk. As previously mentioned, patients seeking care for an acute episode of back pain can be stratified according to their level of risk of chronic-pain-associated disability (see Screening for risk of chronic pain, above), and subsequent interventions are guided by the risk assessment. Consequently, individuals with a low risk are treated with simple, conservative methods such as education, the advice to resume daily activities and re-activation (that is, a programme to regain physical function), which promote healing. Individuals at higher risk receive more complex interventions to address risk factors and prevent further development of the pain and its associated disability problem ${ }^{121,135-138}$.

Historical approaches. Understanding the current treatment recommendations for low back pain is enhanced by examining historical approaches. Until the 1990s, treatment for acute episodes of low back pain often included medical procedures, such as epidural steroid injections, opioid administration, surgery or bed rest; however, these interventions were not more effective than natural recovery, were expensive and were associated with adverse effects ${ }^{139-142}$. Because of increasing injury claims, another previous treatment approach was to provide all individuals seeking care for back pain with an early intervention often consisting of education, physical therapy and exercise, but this did not prevent the development of chronic pain ${ }^{143,144}$. In addition, as psychological factors are prominent risk factors for back pain, several studies have provided psychological counselling to all patients seeking care, although this treatment did not improve outcomes compared with usual care ${ }^{145}$. Analyses of these difficulties suggested two ways forward: targeting interventions on the basis of risk factors to identify individuals with a high risk of developing further pain-associated disability and providing adequate interventions that specifically address the relevant issues, including psychological and social risk factors that have been identified ${ }^{116,146,147}$.

Risk-guided treatment. Targeting treatments for low back pain to the risk profile of a patient is speculated to lead to better outcomes, although the research on individualized treatments is complicated and robust studies are rare. In one trial, targeting therapeutic interventions on the basis of patients' risk was superior to treatment as usual in primary care with regard to function and costs, although the effect size at 1 year was small $(0.19)^{148}$. The selection of a preventive intervention has varied, but the need to address psychological and social factors is evident $t^{125,149,150}$.

In individuals with low risk who have no specific spinal pathology, clinical guidelines for the management of nonspecific low back pain in primary care recommend advising the patient to return to normal activities as soon as possible, in addition to self-managed methods of pain relief and education about the causes and possible selfmanagement of the pain ${ }^{109,151}$. Individuals at medium risk should be monitored to enable rapid response to recurrences or lack of improvement.
Individuals at high risk require special attention. Although these patients might initially have sought medical attention for an acute pain episode, the episode might reflect an exacerbation of a recurrent, well-established condition; whether this is the case can usually be ascertained in a clinical interview. Individuals at high risk should not delay intervention in the hope of full recovery as it greatly increases the risk of chronicpain-associated disability; if targets for intervention are not clear in these patients, further psychosocial assessment is warranted before proceeding. In addition, offering high-risk patients a psychologically informed treatment appears important for successful resolution of the pain problem ${ }^{152}$. Although the treatment of patients at high risk can be challenging, results are quite encouraging when the intervention is targeted towards the specific psychological and social risk factors, although this is under-researched ${ }^{116,136,148,152-154}$.

As part of the management of high-risk patients, one approach has been to offer a psychologically informed prevention programme as an adjunct to medical care that includes reassurance that the condition is not harmful and education about the importance of being active $^{155}$. At high risk, patients are offered a cognitivebehavioural therapy prevention programme that aims to eliminate barriers to activity and work. This programme typically includes techniques to empower the patient, through, for example, re-activation (that is, regaining physical function), learning how to reduce the bothersomeness of pain and stress through self-management and solving problems as they arise (for example, applying these techniques to new situations and dealing with flare-ups $)^{116,121,156}$. A series of studies have demonstrated a reduction in work disability and health-care utilization for between 1 and 5 years in high-risk patients stratified using the ÖMPSQ and then treated with a standardized cognitive-behavioural therapy programme ${ }^{156-160}$. Other psychologically informed treatments based on cognitive-behavioural therapy principles ${ }^{161}$ in primary care have also shown encouraging, albeit smaller, effects ${ }^{116,162}$. To increase the accessibility of psychologically informed interventions, these programmes have been delivered by other trained health-care professionals, such as physical therapists ${ }^{135,163}$. Administering this treatment only to patients at higher risk of chronic pain is more efficient as trials that delivered psychologically informed treatment to patients at any risk yielded disappointing results compared with usual treatment ${ }^{116,163-165}$.

In terms of preventing pain-related work disability, providing work accommodations (such as modified return to work) and communication with the workplace has been found to be effective ${ }^{166-170}$. For example, in one study, workers at high risk were randomized to usual care or a programme providing both the worker and her/his supervisor skills training in communication and problem-solving ${ }^{128}$; the programme reduced work absences and health-care utilization whereas improving overall health compared with usual care. Similarly, a programme to enhance communication between patients and their work supervisors was evaluated among high-risk patients seeking primary care and significantly increased work ability ${ }^{171}$. 


\section{Stepped-care approach}

Non-pharmacological treatments. Compared with previous guidelines for the management of patients with nonspecific back pain, more recent guidelines from the United Kingdom ${ }^{172}$, United States ${ }^{173}$, Belgium ${ }^{174}$ and Denmark ${ }^{175}$ recommend self-management, exercise and physical therapies, before pharmacological treatment, for the treatment of back pain. These changes are driven partly by new data on treatment effectiveness but also by concern about the potential for harm with some pain medicines, such as opioids ${ }^{176}$ and NSAIDs ${ }^{177}$. Supervised exercise programmes are effective for the prevention of low back pain ${ }^{131}$ and for managing chronic, but not acute, low back pain ${ }^{178}$. The form of exercise programme does not seem to be particularly important, as many forms of exercise are beneficial, including yoga, tai chi, motor control exercise, graded activity and pilates, although for both prevention and management the exercise programmes were usually not confined to local spine exercises but focused on the whole body and included strengthening, stretching, cardiovascular and coordination exercises. Exercise is normally contraindicated only in patients with low back pain that arises from a serious pathology, such as a fracture or infection; however, caution or adaptation of the exercise programme might be necessary if patients have a comorbidity, such as respiratory or cardiovascular disease $\mathrm{e}^{178}$.

Across these guidelines, the recommendations for non-pharmacological care of chronic low back pain are fairly consistent. For all patients with pain, initial care should comprise education about the causes and self-management of pain, reassurance, encouragement to remain active and advice on self-care options (such as relaxation or yoga). Patients who fail to respond to this approach or patients who require more complex or intensive care (based on risk assessment) can receive additional treatments such as structured exercises, spinal manipulation or cognitive-behavioural treatment. The types of effective treatments for acute low back pain are different from those for chronic low back pain. Electrotherapy, manual traction and belts, corsets or foot orthotics are not recommended for either acute or chronic pain.

Pharmacological treatments. Acute ( $<3$ months duration) and chronic ( $>3$ months duration) nonspecific low back pain and radicular syndromes have different pharmacological treatment approaches, although a stepped approach is recommended for both. Although traditionally failure to respond to initial, simple approaches was the indication to try a more complex treatment (an approach analogous to the WHO analgesic ladder), more recent research has challenged this approach, as some medicines are ineffective for low back pain (such as paracetamol) $)^{179}$ and other therapies have unknown efficacy (such as opioids for acute low back pain) ${ }^{180}$. A small range of pain medications are recommended for nonspecific low back pain in guidelines from the United States ${ }^{173}$. NSAIDs or muscle relaxants can be considered in individuals with acute low back pain who did not respond to non-pharmacological treatments, with an NSAID at the lowest possible dose for the shortest duration possible as the first option.

In chronic low back pain, head-to-head trials of NSAIDs have not shown a difference in pain relief; there are no data on cyclooxygenase-2 (COX2)-selective NSAIDs. NSAID use should be accompanied by monitoring of the patient's risk factors for gastrointestinal disorders, and gastrointestinal protective treatments should be commenced if warranted. Tramadol or duloxetine are second-line pharmacological options for chronic pain, although opioids are recommended only if the potential benefits outweigh the risks for individual patients and after a discussion of known risks and realistic benefits with patients. Strong opioids are associated with a small short-term improvement, although there is no difference in pain reduction when long-acting or short-acting opioids are used. Weak opioids, such as tramadol, used in combination with paracetamol (acetaminophen) can be used for acute back pain and when NSAIDs are contraindicated, not tolerated or have no effect. By contrast, the UK guidelines do not recommend the use of paracetamol as monotherapy, opioids, tricyclic antidepressants or serotonin and noradrenaline reuptake inhibitors for acute and chronic low back pain ${ }^{172}$. Selective serotonin reuptake inhibitors and muscle relaxants are contradicted for acute and chronic back pain. Anticonvulsants are not recommended for low back pain ${ }^{181}$.

\section{Management of specific pain causes}

Radiofrequency facet denervation. For low back pain originating from the lumbar facet joints, the target for interventional treatment is the medial branch of the dorsal ramus, which innervates the facet joints. A facet joint nerve block using a local anaesthetic is performed to determine whether pain is partly caused by facet joint involvement ${ }^{59,182}$; if confirmed, patients can be offered a radiofrequency denervation of the medial branch of the dorsal ramus to try and achieve long-term pain relief. National Institute for Health and Care Excellence (NICE) guidelines from the United Kingdom ${ }^{183}$ recommend considering radiofrequency denervation only when the main source of pain originates from the facet joints, when pain is moderate to severe, and only when evidence-based multidisciplinary treatment has failed. However, one study that included three RCTs failed to demonstrate any superiority with adding radiofrequency denervation to a standardized exercise programme for the treatment of low back pain originating from the facet joints ${ }^{184}$. The latter study elicited a scientific debate regarding the methods and interpretation used ${ }^{185-187}$. At present, this uncertainty is not resolved.

Managing radicular syndromes. Whether common oral pain medications should be used for radicular syndromes is uncertain ${ }^{188}$. The use of gabapentinoids for this indication has increased, although one trial demonstrated no benefit of pregabalin over placebo ${ }^{189}$. For acute or subacute radicular pain lasting for $>2-3$ weeks, epidural corticosteroid combined with local anaesthetic administration can be considered ${ }^{62}$. Therapies can be delivered to the epidural space in two routes - interlaminar or transforaminal - of which the latter was associated 
with more effective drug delivery to the nerve $\operatorname{root}^{190}$. Epidural injection of local anaesthetic and corticosteroids can reduce radicular pain and might also reduce the number of surgical candidates ${ }^{191}$. Considering the high risk of intravascular injection when attempting to reach the epidural space, the use of imaging guidance is obligatory during this procedure. In addition, this treatment is an off-label use of corticosteroids; thus, written informed consent from the patient is mandatory.

Surgery. No guidelines recommend surgery for the treatment of nonspecific low back pain as in the absence of a clear anatomical basis of low back pain, there is no surgical target. UK guidelines ${ }^{172}$ recommend spinal decompression for patients with radicular low back pain that is potentially caused by degenerative disc disease when non-surgical treatment has not improved pain or function. UK guidelines specifically advise against disc replacement surgery for patients with disc degeneration and advocate that spinal fusion for disc degeneration and/or facet joint-related pain should be used only in RCTs.

\section{Multidisciplinary interventions for chronic pain}

A multidisciplinary approach is recommended for individuals with chronic low back pain. These programmes usually adopt a biopsychosocial approach; involve a combination of educational, physical, cognitive, behavioural, social and/or work-related components; and are often delivered by a team of health-care providers with expertise in different fields. Most programmes include a graded activity approach ${ }^{192}$, whereby patients are encouraged to gradually increase their activity levels towards individualized life goals and to reduce the amounts of rest and drug intake. Such multidisciplinary interventions were more effective than usual care and physical treatments at decreasing pain and disability in one Cochrane systematic review and meta-analysis and were more effective in terms of work outcomes than physical treatment ${ }^{193}$. Given the multi-component nature of these interventions, there is a need for identifying the precise mechanisms of action. Knowledge about the specific components that are required for treatment efficacy and the corresponding dose will inform the development of treatments with improved cost-effectiveness ${ }^{194,195}$.

One novel and more specific multidisciplinary treatment for non-specific low back pain is aimed at directly challenging the catastrophic misinterpretations of pain and various expectations about the relationship between physical activities and pain and/or back injury. The treatment is designed to create harm expectation violations (or prediction errors) by exposing patients to movements or activities that they consider harmful or that they predicted to increase pain ${ }^{196}$. During treatment, these individuals' predictions are challenged and brought in line with the incoming sensory and safety information, which provides an opportunity for learning new and more accurate predictions. Such treatments can considerably reduce levels of pain-related fear ${ }^{197}$ and the perceived harmfulness of physical activities ${ }^{198}$ and are costeffective ${ }^{199}$. However, the effects of these treatments on disability levels were no different than a graded activity approach $^{197}$, except when the intervention was studied in replicated single-case experiments ${ }^{200-202}$. A possible reason for this difference is that the latter included personalized measures of disability and goals whereas the RCTs used standard or global outcome measures ${ }^{108}$.

\section{Societal interventions}

Treating individual patients with low back pain might not be sufficient to address the most disabling health condition globally ${ }^{203,204}$. As previously mentioned, low back pain is highly prevalent and is strongly influenced by patient beliefs and expectations, in addition to societal contingencies such as compensation and disability policies. Back pain is also commonly mismanaged ${ }^{205}$. Societal-level interventions to improve back pain health outcomes include mass media campaigns to improve the understanding of low back pain in the general public $^{206,207}$, addressing the fears and expectations of health-care providers ${ }^{208,209}$, removing compensation and disability policies that encourage disability and implementation studies that attempt to address important evidence-practice gaps ${ }^{210}$.

\section{Quality of life}

Back pain has considerable negative effects on the quality of life of affected individuals. Individuals with new-onset back pain have an increased risk of lower quality of life scores ${ }^{211}$, and the negative effect on quality of life increases with persistent pain ${ }^{211}$. Patients with chronic back pain report a quality of life that is lower than individuals without pain and that is comparable to those of individuals with life-threatening diagnoses ${ }^{212,213}$. In addition, back pain is associated with worry and fears, particularly about the (sense of) self and social relationships and especially when pain persists longer than expected $^{214,215}$. In one study, back pain was summarized as the psychological effect of the unpredictable omnipresent nature of pain, which is unpredictable for the self, wellness and the future ${ }^{216}$. Population and patient cohort studies have demonstrated associations between back pain and other problems, such as functional disability, anxiety, depression, fearful beliefs about the meaning of pain, (work-related) avoidance behaviour, stress, increased health-care utilization, insomnia, reporting of more somatic comorbidity and unemployment ${ }^{211,217}$.

Given the effect of back pain on quality of life, the multidimensional assessment of health-related quality of life is increasingly acknowledged as indispensable for the study of back pain ${ }^{212,218}$. The generic 36-item Short Form Health Survey ${ }^{219}$, which includes 8 dimensions of health summarized in a mental and physical component score, is recommended to assess the self-reported health state of patients with back pain. The generic and cross-cultural nature of this survey allows comparisons between various studies.

Owing to previous data, and the acceptance of the biopsychosocial approach to back pain, persistent back pain is considered a health condition that is affected by a combination of physical, psychological, environmental, cultural and social factors ${ }^{218}$. In fact, these factors might affect the perceived quality of life more than the pain itself $^{217}$. In addition, negative beliefs such as catastrophic 
misinterpretations of pain and expectancies about the inability to predict and to control pain are strong correlates of quality of life in individuals with back pain ${ }^{99,212,217}$. Leaving these factors unchallenged can result in a risk of a higher disease burden 220 .

\section{Outlook}

Despite an exponential increase in research on the epidemiology, mechanisms and treatment of low back pain, and increased consensus among international guidelines, serious challenges remain. The large variability in clinical presentation, a wide range of course and prognosis, insufficient understanding of the underlying mechanisms and limited success in identifying effective treatments make low back pain a challenge for clinicians and researchers. However, increasing efforts are focusing on promising research avenues.

\section{Risk factors}

Although the research into the risk factors for low back pain has shifted from a pathophysiological towards a biopsychosocial perspective, improvements are still needed. For example, the current data might be misleading as most epidemiological studies have included a selected group of individuals in which those from lowincome and middle-income countries, young individuals and elderly individuals are under-represented ${ }^{221}$. Also, the focus of studies has mainly been on the level of the individual beliefs, emotions and behaviour of the person with back pain, and extending these towards both extremes of the biopsychosocial realm might increase their effectiveness - modifiable biological risk factors (for example, epigenetic mechanisms in the acuteto-chronic pain transitioning) and societal risk factors (for example, workplace and family responses, and health-care providers' beliefs and attitudes). Experiencedependent regulation of gene expression might mediate responses to acute physical or mental stressors and could help in the development of tools for the early identification of risk and severity assessment in complex cases ${ }^{222}$. On the other end of the spectrum, understanding the role of the negative expectations and social context factors that surround the individual with low back pain may be as important understanding those of the patient. Health-care providers' recommendations for activity and return to work vary widely and reflect their personal expectancies towards back pain and not necessarily the patients' clinical and work conditions ${ }^{223,224}$. Accordingly, future research should test whether these potentially iatrogenic expectancies, which could perhaps be introduced as novel 'white' flags, directly or indirectly influence patients' outcomes.

Positive resilience factors that might protect against the development of chronic low back pain and disability have been identified and are under study. To this end, resilience is not merely characterized by the absence of risk factors or pathology but is considered a dynamic process that enables the individual to flexibly adapt to severe adversity over the life course ${ }^{225}$. Studying how resilience buffers against the influence of risk factors might increase the precision of our prediction models in low back pain.

\section{Neurobiology}

Several aspects of the role of the brain in back pain require further investigation. For example, the specificity of previous findings must be established to differentiate changes specific to back pain from those reflecting chronic pain more generally or from processes associated with (chronic) back pain. Direct comparisons between chronic pain conditions within the same study should identify syndrome-specific alterations, but results from these studies should be interpreted with caution as causality is extremely difficult to establish ${ }^{226}$. In addition, further longitudinal studies are needed to identify which alterations in brain structure and function underlie the transition to chronic back pain and which are the result or a correlate of an already established chronification. Moreover, most studies have focused on pain intensity ratings as the most relevant behavioural parameter in back pain; however, this disorder is also characterized by profound alterations in behaviour (such as avoidance of painful movement), which might be induced and maintained by independent brain networks; these factors also require further study. Finally, psychological processes underlying alterations in corticolimbic structures need to be differentiated and characterized in more detail to enable stratification in the prevention and treatment of chronic back pain.

\section{Management}

Although several management options are available for low back pain, current systematic reviews and metaanalyses reveal small effect sizes (often not exceeding $0.50)^{227}$. At least three ways of improving the care of individuals with back pain have been proposed. One is personalizing treatments by testing in whom what treatment works and how the treatment works ${ }^{228-230}$; the treatment can then be offered to the patient who is expected to benefit from that particular treatment. This process might improve efficacy by more systematically identifying the mechanisms underlying the treatment outcomes. Second, stratified models of care exist and have some evidence they are superior to non-stratified primary care ${ }^{231}$. Stratification can be based on symptom duration (stepped approach) or on the result of a risk assessment (risk stratification approach) (FIG. 6). Third, the replicated Single-Case Experimental Design (SCED) is another underutilized methodology and might improve the care of patients with back pain ${ }^{232,233}$. An SCED is an interrupted time series design in which one patient is observed repeatedly during a certain time frame under different levels (for example, baseline versus treatment) of at least one outcome. SCEDs are flexible, are fairly easy to implement in the practice of health care, elegantly bridge the gap between research and practice, and have available methodological quality standards $\mathrm{s}^{234,235}$.

In addition to these novel approaches, there is also a need for cost-effective technologies that can improve the global reach of evidence-based interventions for low back pain. Among such interventions are lowtech booklets or more advanced eHealth and mHealth approaches implemented via the Internet and using virtual reality technologies or gaming platforms that 
can be used via mobile and wireless applications ${ }^{236,237}$ Using similar methodology, evidence-based messages supporting self-management could be disseminated using social media and smartphone technology ${ }^{238}$. This technology is still largely uncharted territory but is likely to be promising. Finally, novel back pain management approaches are needed that also reach socio-economically vulnerable groups, such as ethnic minorities and individuals with low literacy, low educational attainment and low income ${ }^{239}$.

Published online: 13 December 2018
1. Kongsted, A., Kent, P., Axen, I., Downie, A. S. \& Dunn, K. M. What have we learned from ten years of trajectory research in low back pain? BMC Musculoskelet. Disord. 17, 220 (2016).

2. Kamaleri, Y., Natvig, B., Ihlebaek, C. M. \& Bruusgaard, D. Does the number of musculoskeletal pain sites predict work disability? A 14-year prospective study. Eur. J. Pain 13, 426-430 (2009).

3. Von Korff, M. et al. Chronic spinal pain and physicalmental comorbidity in the United States: results from the national comorbidity survey replication. Pain 113 , 331-339 (2005).

4. Hartvigsen, J. et al. What low back pain is and why we need to pay attention. Lancet 391, 2356-2367 (2018).

5. Walker, B. F., Muller, R. ¿ Grant, W. D. Low back pain in Australian adults: the economic burden. Asia Pac. J. Publ. Health 15, 79-87 (2003).

6. Maetzel, A. \& Li, L. The economic burden of low back pain: a review of studies published between 1996 and 2001. Best Pract. Res. Clin. Rheumatol. 16, 23-30 (2002).

7. Dagenais, S., Caro, J. \& Haldeman, S. A systematic review of low back pain cost of illness studies in the United States and internationally. Spine J. 8, 8-20 (2008).

8. Maniadakis, N. \& Gray, A. The economic burden of back pain in the UK. Pain 84, 95-103 (2000).

9. van Tulder, M. W., Koes, B. W. \& Bouter, L. M. A costof-illness study of back pain in The Netherlands. Pain 62, 233-240 (1995).

10. Treede, R. et al. Chronic pain as a symptom or a disease: the IASP classification of chronic pain for the International Classification of Diseases ICD-11. Pain 160 19-27 (2019)

11. Nicholas, M. et al. The IASP classification of chronic pain for ICD-11: chronic primary pain. Pain 160 28-37 (2019).

12. Katz, J., Rosenbloom, B. N. \& Fashler, S. Chronic pain, psychopathology, and DSM-5 somatic symptom disorder. Can. J. Psychiatry 60, 160-167 (2015).

13. Global Burden of Disease Study 2013 Collaborators Global, regional, and national incidence, prevalence and years lived with disability for 301 acute and chronic diseases and injuries in 188 countries, 1990-2013: a systematic analysis for the Global Burden of Disease Study 2013. Lancet 386, 743-800 (2015)

14. Hoy, D. et al. A systematic review of the global prevalence of low back pain. Arthritis Rheum. 64 2028-2037 (2012).

15. Deyo, R. A. \& Weinstein, J. N. Low back pain. N. Engl. J. Med. 344, 363-370 (2001)

16. Janevic, M. R., McLaughlin, S. J., Heapy, A. A., Thacker, C. \& Piette, J. D. Racial and socioeconomic disparities in disabling chronic pain: findings from the health and retirement study. J. Pain 18, 1459-1467 (2017).

17. Stanton, T. R. et al. After an episode of acute low back pain, recurrence is unpredictable and not as common as previously thought. Spine 33, 2923-2928 (2008).

18. Garcia, J. B. et al. Prevalence of low back pain in Latin America: a systematic literature review. Pain Physician 17, 379-391 (2014)

19. Louw O A. Morris, L. D \& Grimmer-Somers, K The prevalence of low back pain in Africa: a systematic review. BMC Musculoskelet. Disord. 8, 105 (2007).

20. Yiengprugsawan, V. et al. Low back pain and limitations of daily living in Asia: Iongitudinal findings in the Thai cohort study. BMC Musculoskelet. Disord. 18, 19 (2017).

21. Jackson, T., Chen, H., lezzi, T., Yee, M. \& Chen, F Prevalence and correlates of chronic pain in a random population study of adults in Chongqing. China. Clin. J. Pain 30, 346-352 (2014).

22. Dunn, K. M., Hestbaek, L. \& Cassidy, J. D. Low back pain across the life course. Best Pract. Res. Clin. Rheumatol. 27, 591-600 (2013)

23. Calvo-Munoz, I., Gomez-Conesa, A. \& Sanchez-Meca, J. Prevalence of low back pain in children and adolescents: a meta-analysis. BMC Pediatr. 13, 14 (2013).

24. Taimela, S., Kujala, U. M., Salminen, J. J. \& Viljanen, T. The prevalence of low back pain among children and adolescents. A nationwide, cohort-based questionnaire survey in Finland. Spine 22, 1132-1136 (1997).

25. Jeffries, L. J., Milanese, S. F. \& Grimmer-Somers, K. A Epidemiology of adolescent spinal pain: a systematic overview of the research literature. Spine 32 2630-2637 (2007).

26. Dionne, C. E., Dunn, K. M. \& Croft, P. R. Does back pain prevalence really decrease with increasing age? A systematic review. Age Ageing 35, 229-234 (2006).

27. Diatchenko, L., Fillingim, R. B., Smith, S. B. \& Maixner, W. The phenotypic and genetic signatures of common musculoskeletal pain conditions. Nat. Rev. Rheumatol. 9, 340-350 (2013).

28. Taylor, J. B., Goode, A. P., George, S. Z. \& Cook, C. E. Incidence and risk factors for first-time incident low back pain: a systematic review and meta-analysis. Spine J. 14, 2299-2319 (2014).

29. Cook, C. E. et al. Risk factors for first time incidence sciatica: a systematic review. Physiother Res. Int. 19 65-78 (2014).

30. Parreira Pdo, C. et al. Can patients identify what triggers their back pain? Secondary analysis of a case-crossover study. Pain 156, 1913-1919 (2015).

31. El-Metwally, A. et al. Genetic and environmental influences on non-specific low back pain in children: a twin study. Eur. Spine J. 17, 502-508 (2008)

32. Hestbaek, L., lachine, I. A., Leboeuf-Yde, C., Kyvik, K. O. $\&$ Manniche, $C$. Heredity of low back pain in a young population: a classical twin study. Twin Res. 7, 16-26 (2004).

33. Junqueira, D. R. et al. Heritability and lifestyle factors in chronic low back pain: results of the Australian twin low back pain study (The AUTBACK study). Eur. J. Pain 18, 1410-1418 (2014)

34. Kraatari, M., Skarp, S., Niinimaki, J., Karppinen, J. ¿ Mannikko, M. A. Whole exome study identifies novel candidate genes for vertebral bone marrow signal changes (Modic changes). Spine $\mathbf{4 2}$ 1201-1206 (2017).

35. O'Rielly, D. D. et al. Private rare deletions in SEC16A and MAMDC4 may represent novel pathogenic variants in familial axial spondyloarthritis. Ann. Rheum. Dis. 75, 772-779 (2016).

36. Ranganathan, V., Gracey, E., Brown, M. A., Inman, R. D. $\&$ Haroon, N. Pathogenesis of ankylosing spondylitis recent advances and future directions. Nat. Rev. Rheumatol. 13, 359-367 (2017)

37. Ge, T., Chen, C. Y., Neale, B. M., Sabuncu, M. R. \& Smoller, J. W. Correction: phenome-wide heritability analysis of the UK Biobank. PLOS Genet. 14 e1007228 (2018).

38. Meloto, C. B. et al. Human pain genetics database: a resource dedicated to human pain genetics research. Pain 159, 749-763 (2018).

This paper presents the Human Pain Genetics Database (HPGDB), which is one of the first comprehensive variant-focused inventory of genetic contributors to human pain.

39. Williams, F. M. et al. Novel genetic variants associated with lumbar disc degeneration in northern Europeans: a meta-analysis of 4600 subjects. Ann. Rheum. Dis. 72, 1141-1148 (2013)

40. Diatchenko, L., Nackley, A. G., Slade, G. D., Fillingim, R. B. \& Maixner, W. Idiopathic pain disorders-pathways of vulnerability. Pain 123 226-230 (2006).

41. Tegeder, I. et al. GTP cyclohydrolase and tetrahydrobiopterin regulate pain sensitivity and persistence. Nat. Med. 12, 1269-1277 (2006).

42. Nackley, A. G. et al. Human catecholO-methyltransferase haplotypes modulate protein expression by altering mRNA secondary structure. Science 314, 1930-1933 (2006).
43. Nackley, A. G. et al. Catechol-O-methyltransferase inhibition increases pain sensitivity through activation of both $\beta 2$ - and $\beta 3$-adrenergic receptors. Pain 128 , 199-208 (2007).

44. Diatchenko, L. et al. Genetic basis for individual variations in pain perception and the development of a chronic pain condition. Hum. Mol. Genet. 14, 135-143 (2005).

45. Battie, M. C. et al. Lumbar spinal stenosis is a highly genetic condition partly mediated by disc degeneration. Arthritis Rheumatol. 66, 3505-3510 (2014).

46. Battie, M. C. et al. The Twin Spine Study: contributions to a changing view of disc degeneration. Spine J. $\mathbf{9}$, 47-59 (2009).

47. Steffens, D. et al. What triggers an episode of acute low back pain? A case-crossover study. Arthritis Care Res. 67, 403-410 (2015).

48. Bigos, S. J. et al. A prospective evaluation of preemployment screening methods for acute industrial back pain. Spine 17, 922-926 (1992).

49. Brinjikji, W. et al. MRI findings of disc degeneration are more prevalent in adults with low back pain than in asymptomatic controls: a systematic review and meta-analysis. Am. J. Neuroradiol. 36, 2394-2399 (2015).

50. Endean, A., Palmer, K. T. \& Coggon, D. Potential of magnetic resonance imaging findings to refine case definition for mechanical low back pain in epidemiological studies: a systematic review. Spine 36, 160-169 (2011).

51. Wang, Y., Videman, T. \& Battie, M. C. Lumbar vertebral endplate lesions: prevalence, classification, and association with age. Spine 37, 1432-1439 (2012).

52. Wang, Y., Videman, T. \& Battie, M. C. ISSLS prize winner: lumbar vertebral endplate lesions: associations with disc degeneration and back pain history. Spine 37, 1490-1496 (2012).

53. Georgy, M. Stern, M. \& Murphy, K. What is the role of the bacterium propionibacterium acnes in type 1 Modic changes? A review of the literature. Can. Assoc Radiol. J. 68, 419-424 (2017).

54. Crockett, M. T., Kelly, B. S., van Baarsel, S. \& Kavanagh, E. C. Modic type 1 vertebral endplate changes: injury, inflammation, or infection? Am. J. Roentgenol. 209, 167-170 (2017).

55. Feng, Z., Liu, Y., Yang, G., Battie, M. C. \& Wang, Y Lumbar vertebral endplate defects on magnetic resonance images: classification, distribution patterns, and associations with Modic changes and disc degeneration. Spine 43, 919-927 (2017).

56. Dudli, S., Fields, A. J., Samartzis, D., Karppinen, J. \& Lotz, J. C. Pathobiology of Modic changes. Eur. Spine J. 25, 3723-3734 (2016).

57. Dudli, S. et al. Issls prize in basic science 2017 : intervertebral disc/bone marrow cross-talk with Modic changes. Eur. Spine J. 26, 1362-1373 (2017).

58. Kauppila, L I. Atherosclerosis and disc degeneration low-back pain-a systematic review. Eur. J. Vasc. Endovasc. Surg. 37, 661-670 (2009).

59. van Kleef, M. et al. 12. Pain originating from the lumbar facet joints. Pain Pract. 10, 459-469 (2010).

60. Bishop, M. D., Horn, M. E. \& George, S. Z Exercise-induced pain intensity predicted by pre-exercise fear of pain and pain sensitivity. Clin. J. Pain 27, 398-404 (2011).

61. Bishop, M. D., Horn, M. E., Lott, D. J., Arpan, I. \& George, S. Z. Magnitude of spinal muscle damage is not statistically associated with exercise-induced low back pain intensity. Spine J. 11, 1135-1142 (2011).

62. Van Boxem, K. et al. Pulsed radiofrequency: a review of the basic science as applied to the pathophysiology of radicular pain: a call for clinical translation. Reg. Anesth. Pain Med. 39, 149-159 (2014).

63. Jensen, M. C. et al. Magnetic resonance imaging of the lumbar spine in people without back pain. N. Engl. J. Med. 331, 69-73 (1994). 
64. Kregel, J. et al. Structural and functional brain abnormalities in chronic low back pain: a systematic review. Semin. Arthritis Rheum. 45, 229-237 (2015).

65. Schmidt-Wilcke, T. et al. Affective components and intensity of pain correlate with structural differences in gray matter in chronic back pain patients. Pain 125 89-97 (2006)

66. Seminowicz, D. A. et al. Effective treatment of chronic low back pain in humans reverses abnormal brain anatomy and function. J. Neurosci. 31, 7540-7550 (2011)

67. Apkarian, A. V. et al. Chronic back pain is associated with decreased prefrontal and thalamic gray matter density. J. Neurosci. 24, 10410-10415 (2004).

68. Baliki, M. N. et al. Corticostriatal functional connectivity predicts transition to chronic back pain Nat Neurosci. 15, 1117-1119 (2012).

69. Tagliazucchi, E., Balenzuela, P., Fraiman, D. $\&$ Chialvo, D. R. Brain resting state is disrupted in chronic back pain patients. Neurosci. Lett. 485 26-31 (2010).

70. Giesecke, T. et al. Evidence of augmented central pain processing in idiopathic chronic low back pain. Arthritis Rheum. 50, 613-623 (2004).

71. Yu, R. et al. Disrupted functional connectivity of the periaqueductal gray in chronic low back pain. Neuroimage Clin. 6, 100-108 (2014).

72. Vachon-Presseau, E. et al. Corticolimbic anatomical characteristics predetermine risk for chronic pain. Brain 139, 1958-1970 (2016).

73. Berger, S. E. et al. Hippocampal morphology mediates biased memories of chronic pain. Neuroimage 166, 86-98 (2018)

74. Martikainen, I. K. et al. Chronic back pain is associated with alterations in dopamine neurotransmission in the ventral striatum. J. Neurosci. 35, 9957-9965 (2015)

75. Mutso, A. A. et al. Reorganization of hippocampa functional connectivity with transition to chronic back pain. J. Neurophysiol. 111, 1065-1076 (2014).

76. Petre, B. et al. Smoking increases risk of pain chronification through shared corticostriatal circuitry. Hum. Brain Mapp. 36, 683-694 (2015)

77. Hashmi, J. A. et al. Shape shifting pain: chronification of back pain shifts brain representation from nociceptive to emotional circuits. Brain 136 , 2751-2768 (2013)

This is a longitidinal brain imaging study following patients with subacute back pain over a 1-year period showing large-scale shifts in brain activity with the transition to chronic pain, with increased activity in emotion-related circuitry in nonrecovered patients

78. Pijnenburg, M. et al. Structural brain connectivity and the sit-to-stand-to-sit performance in individuals with nonspecific low back pain: a diffusion magnetic resonance imaging-based network analysis. Brain Connect. 6, 795-803 (2016).

79. Mano, H. et al. Classification and characterisation of brain network changes in chronic back pain: a multicenter study. Wellcome Open Res. 3, 19 (2018)

80. Mansour, A. et al. Global disruption of degree rank order: a hallmark of chronic pain. Sci. Rep. 6, 34853 (2016).

81. Wall, P. D. On the relation of injury to pain. The John J. Bonica lecture. Pain 6, 253-264 (1979).

82. Sharot, T. $\&$ Garrett, N. Forming beliefs: why valence matters. Trends Cogn. Sci. 20, 25-33 (2016).

83. Petzschner, F. H. Weber, L. A. E. Gard, T \& Stephan, K. E. Computational psychosomatics and computational psychiatry: toward a joint framework for differential diagnosis. Biol. Psychiatry $\mathbf{8 2}$, 421-430 (2017)

84. Wiech, K. Deconstructing the sensation of pain: the influence of cognitive processes on pain perception. Science 354, 584-587 (2016) This review addresses the critical role of expectations on pain perception and their modification through learning.

85. Wiech, K. et al. Influence of prior information on pain involves biased perceptual decision-making. Curr. Biol. 24, R679-R681 (2014)

86. Moseley, G. L. \& Arntz, A. The context of a noxious stimulus affects the pain it evokes. Pain 133, 64-7 (2007).

87. Van den Bergh, O., Witthoft, M., Petersen, S. \& Brown, R. J. Symptoms and the body: taking the inferential leap. Neurosci. Biobehav. Rev. 74, 185-203 (2017).
88. Moseley, G. L. $\&$ Vlaeyen, J. W. Beyond nociception: the imprecision hypothesis of chronic pain. Pain 156 35-38 (2015)

89. Sullivan, M., Thorn, B., Haythornthwaite, J., Keefe, F. $\&$ Bradley, M. Theoretical perspectives on the relation between catastrophizing and pain. Clin. J. Pain 17, 52-64 (2001)

90. Vlaeyen, J. W. \& Linton, S. J. Fear-avoidance and its consequences in chronic musculoskeletal pain: a state of the art. Pain 85, 317-332 (2000).

91. Vlaeyen, J. W. \& Linton, S. J. Fear-avoidance model of chronic musculoskeletal pain: 12 years on. Pain 153 . 1144-1147 (2012) This is an updated narrative review on the fear-avoidance model of chronic musculoskeletal pain.

92. Waddell, G., Newton, M., Henderson, I., Somerville, D. \& Main, C. J. A. Fear-Avoidance Beliefs Questionnaire (FABO) and the role of fear- avoidance beliefs in chronic low back pain and disability. Pain $\mathbf{5 2}$ 157-168 (1993).

93. Lethem, J., Slade, P. D., Troup, J. D. \& Bentley, C. Outline of a fear-avoidance model of exaggerated pain perception-I. Behav. Res. Ther. 21, 401-408 (1983).

94. Zale, E. L., Lange, K. L., Fields, S. A. \& Ditre, J. W. The relation between pain-related fear and disability: a meta-analysis. J. Pain 14, 1019-1030 (2013).

95. Wertli, M. M. et al. Fear-avoidance beliefs-a moderato of treatment efficacy in patients with low back pain: a systematic review. Spine J. 14, 2658-2678 (2014).

96. Lee, $\mathrm{H}$. et al. How does pain lead to disability? A systematic review and meta-analysis of mediation studies in people with back and neck pain. Pain 156, 988-997 (2015)

97. Vlaeyen, J.W. Learning to predict and control harmful events: chronic pain and conditioning. Pain 156 (Suppl. 1), S86-S93 (2015)

98. Van Vliet, C., Meulders, A., Vancleef, L. \& Vlaeyen, J. W. Avoidance behavior can paradoxically increase fear. J. Pain 19, 1222-1230 (2018).

99. Vlaeyen, J. W., Morley, S. \& Crombez, C. The experimental analysis of the interruptive, interfering, and identity-distorting effects of chronic pain. Behav. Res. Ther. 86, 23-34 (2016).

100. Schneider, C., Palomba, D. \& Flor, H. Pavlovian conditioning of muscular responses in chronic pain patients: central and peripheral correlates. Pain 112, 239-247 (2004)

101. Meulders, A., Vansteenwegen, D. \& Vlaeyen, J. W. The acquisition of fear of movement-related pain and associative learning: a novel pain-relevant human fear conditioning paradigm. Pain 152, 2460-2469 (2011).

102. Diesch, E. \& Flor, H. Alteration in the response properties of primary somatosensory cortex related to differential aversive Pavlovian conditioning. Pain 131 171-180 (2007).

103. Meulders, A., Jans, A. \& Vlaeyen, J. W. Differences in pain-related fear acquisition and generalization: an experimental study comparing patients with fibromyalgia and healthy controls. Pain 156 108-122 (2015)

104. Madden, V. J. et al. Pain by association? Experimental modulation of human pain thresholds using classical conditioning. J. Pain 17, 1105-1115 (2016).

105. Wand, B. M. et al. Cortical changes in chronic low back pain: current state of the art and implications for clinical practice. Man. Ther. 16, 15-20 (2011)

106. Gatzounis, R., Schrooten, M. G., Crombez, G. \& Vlaeyen, J. W. Operant learning theory in pain and chronic pain rehabilitation. Curr. Pain Headache Rep. 16, 117-126 (2012)

107. Flor, H., Knost, B. \& Birbaumer, N. The role of operant conditioning in chronic pain: an experimental investigation Pain 95, 111-118 (2002).

108. Morley, S. Efficacy and effectiveness of cognitive behaviour therapy for chronic pain: progress and some challenges. Pain 152, S99-S106 (2011)

109. Koes, B. W. et al. An updated overview of clinical guidelines for the management of non-specific low back pain in primary care. Eur. Spine J. 19 2075-2094 (2010).

110. Downie, A. et al. Red flags to screen for malignancy and fracture in patients with low back pain: systematic review. BMJ 347, f7095 (2013).

111. Henschke, N. et al. Prevalence of and screening for serious spinal pathology in patients presenting to primary care settings with acute low back pain Arthritis Rheum. 60, 3072-3080 (2009).
112. Henschke, N. et al. Prevalence of and screening for serious spinal pathology in patients presenting to primary care with acute low back pain. Arthritis Rheum. 60, 3072-3080 (2009).

113. Australian Acute Musculoskeletal Pain Guidelines Group. Evidence-Based Management of Acute Musculoskeletal Pain. A Guide for Clinicians 1st edn (Australian Academic Press Pty Ltd, 2004).

114. Verhagen, A. P., Downie, A., Popal, N., Maher, C. \& Koes, B. W. Red flags presented in current low back pain guidelines: a review. Eur. Spine J. 25, 2788-2802 (2016).

115. Maher, C., Underwood, M. \& Buchbinder, R. Non-specific low back pain. Lancet 389, 736-747 (2017).

116. Nicholas, M. K., Linton, S. J., Watson, P. J. $\&$ Main, C. J. Early identification and management of psychological risk factors ("yellow flags") in patients with low back pain: a reappraisal. Phys. Ther. $\mathbf{9 1}$, 737-753 (2011)

This paper addresses the influence of the yellow flags on outcome in people with acute or subacute low back pain and whether yellow flags be targeted in interventions to improve outcomes.

117. Chou, R., Qaseem, A., Owens, D. K. \& Shekelle, P. Diagnostic imaging for low back pain: advice for high-value health care from the American College of Physicians. Ann. Intern. Med. 154, 181-189 (2011)

118. Menezes Costa, L. D. C. et al. The prognosis of acute and persistent low-back pain: a meta-analysis. CMAJ 184, E613-E624 (2012).

119. Itz, C., Geurts, J., Kleef, M. v. \& Nelemans, P. Clinical course of non-specific low back pain: a systematic review of prospective cohort studies set in primary care. Eur. J. Pain 17, 5-15 (2013)

120. Hoy, D. et al. The global burden of low back pain: estimates from the Global Burden of Disease 2010 study. Ann. Rheum. Dis. 73, 968-974 (2014).

121. Linton, S., Flink, I. \& Vlaeyen, J. Understanding the etiology of chronic pain from a psychological perspective. Phys. Ther. 98, 315-324 (2018).

122. Aaras, A. The impact of ergonomic intervention on individual health and corporate prosperity in a telecommunications environment. Ergonomics 37, 1679-1696 (1994).

123. Linton, S. \& Boersma, K. Early identification of patients at risk of developing a persistent back problem: the predictive validity of the Örebro Musculoskeletal Pain Questionnaire. Clin. J. Pain 19, 80-86 (2003).

124. Hill, J. C. et al. A primary care back pain screening tool: Identifying patient subgroups for initial treatment. Arthritis Rheum. 59, 632-641 (2008).

125. Gatchel, R. J., Peng, Y. B., Peters, M. L., Fuchs, P. N. \& Turk, D. C. The biopsychosocial approach to chronic pain: scientific advances and future directions. Psychol. Bull. 133, 581-624 (2007).

126. Karran, E. L. et al. Can screening instruments accurately determine poor outcome risk in adults with recent onset low back pain? A systematic review and meta-analysis. BMC Med. 15, 13 (2017).

127. Nicholas, M. K. et al. Predicting return to work in a heterogeneous sample of recently injured workers using the brief OMPSQ-SF. J. Occup. Rehabil. https://doi.org/10.1007/s 10926-018-9784-8 (2018)

128. Linton, S., Boersma, K., Traczyk, M., Shaw, W. \& Nicholas, M. Early workplace communication and problem solving to prevent back disability: results of a randomized controlled trial among high-risk workers and their supervisors. J. Occup. Rehabil. 26 150-159 (2016)

129. Waddell, G. A new clinical model for the treatment of low-back pain. Spine 12, 632-644 (1987).

130. Daltroy, L. H. et al. A controlled trial of an educational program to prevent low back injuries. N. Engl. J. Med 337, 322-328 (1997)

131. Steffens, D. et al. Prevention of low back pain: a systematic review and meta-analysis. JAMA Intern. Med. 176, 199-208 (2016) This systematic review and meta-analysis shows that exercise alone or in combination with education is effective for preventing low back pain

132. Garber, C. E. et al. American College of Sports Medicine position stand. Quantity and quality of exercise for developing and maintaining cardiorespiratory, musculoskeletal, and neuromotor fitness in apparently healthy adults: guidance for prescribing exercise. Med.Sci. Sports Ex. 43 1334-1359 (2011).

133. Kellett, K., Kellett, D. \& Nordholm, L. Effects of an exercise program on sick leave due to back pain. Phys. Ther. 71, 283-293 (1991). 
134. Machado, G. C., Rogan, E. \& Maher, C. G. Managing non-serious low back pain in the emergency department: time for a change? Emerg. Med. Australas. 30, 279-282 (2017).

135. Main, C. J. \& George, S. Z. Psychologically informed practice for management of low back pain: future directions in practice and research. Phys. Ther. 91 820-824 (2011)

36. Linton, S. J., Nicholas, M. \& Shaw, W. Why wait to address high-risk cases of acute low back pain? A comparison of stepped, stratified, and matched care Pain 159, 2437-2441 (2018).

137. Linton, S. J. New Avenues for the Prevention of Chronic Musculoskeletal Pain Vol. 1306 (Elsevier Science, Amsterdam, 2002).

138. Nicholas, M. K. \& George, S. Z. Psychologically informed interventions for low back pain: an update for physical therapists. Phys. Ther. 91, 765-776 (2011)

139. Malmivaara, A. et al. The treatment of acute low back pain-bed rest, exercises, or ordinary activity? N. Engl. J. Med. 332, 351-355 (1995). This RCT reveals that in patients with acute low back pain, continuing ordinary activities leads to more rapid recovery than either bed rest or back-mobilizing exercises.

140. Waddell, G. The Back Pain Revolution 2nd edn (Churchill-Livingstone, 2004).

141. Waddell, G., Aylward, M. \& Sawney, P. Back Pain, Incapacitiy for Work and Social Security Benefits: an International Literature Review and Analysis (The Royal Society of Medicine Press, 2002).

142. Deyo, R. A., Mirza, S. K., Turner, J. A. \& Martin, B. I. Overtreating chronic back pain: time to back off? J. Am. Board Family Med. 22, 62-68 (2009).

143. Sinclair, S. J. \& Hogg-Johnson, S. in New Avenues for the Prevention of Chronic Musculoskeletal Pain and Disability (ed. Linton, S. J.) 259-268 (Elsevier, 2002).

144. UK BEAM Trial Team. United Kingdom back pain exercise and manipulation (UK BEAM) randomised trial: effectiveness of physical treatments for back pain in primary care. BMJ 329, 1377 (2004)

145. Jellema, P. et al. Should treatment of (sub) acute low back pain be aimed at psychosocial prognostic factors? Cluster randomised clinical trial in general practice. BMJ 331, 84 (2005)

146. Jellema, $P$. et al. Why is a treatment aimed at psychosocial factors not effective in patients with (sub) acute low back pain? Pain 118, 350-359 (2005)

147. van der Windt, D., Hay, E., Jellema, P. \& Main, C. Psychosocial interventions for low back pain in primary care: lessons learned from recent trials. Spine 33, 81 (2008)

148. Hill, J. C. et al. Comparison of stratified primary care management for low back pain with current best practice (STarT Back): a randomised controlled trial. Lancet 378, 1560-1571 (2011).

This RCT reveals that a stratified approach using prognostic screening with matched pathways is more (cost)effective than non-stratified current best practice.

149. Main C in New Avenues for the Prevention of Chronic Musculoskeletal Pain and Disability (ed. Linton, S. J.) 47-63 (Elsevier, 2002).

150. Mallen, C., Peat, G., Thomas, E., Dunn, K. M. $\&$ Croft, P. R. Prognostic factors for musculosketal pain in primary care: a systematic review. Br. J. Gen. Pract. 57, 655-661 (2007)

151. Traeger, A. C. et al. Effect of Primary Care-Based Education on Reassurance in Patients With Acute Low Back Pain: Systematic Review and Meta-analysis. JAMA. Intern. Med. 175, 733-743 (2015).

152. Linton, S. J. in Psychological Approaches to Pain Management: a Practitioner's Handbook (eds Turk, D. C. \& Gatchel, R. J.) (Guildord Press, 2018)

153. Nicholas, M. Preventing disabling chronic pain by engaging psychologists in the acute phase. APS https://www.psychology.org.au/inpsych/2016/august/ nicholas/ (2016).

154. Foster, N. E. et al. Effect of stratified care for low back pain in family practice (IMPaCT Back): a prospective population-based sequential comparison. Ann. Fam. Med. 12, 102-111 (2014).

155. Traeger, A. C. et al. Effect of primary care-based education on reassurance in patients with acute low back pain: systematic review and meta-analysis. JAMA Intern. Med. 175, 733-743 (2015).

156. Van Den Hout, J. H., Vlaeyen, J. W., Heuts, P. H. Zijlema, J. H. \& Wijnen, J. A. Secondary prevention of work-related disability in nonspecific low back pain: does problem-solving therapy help? A randomized clinical trial. Clin. J. Pain 19, 87-96 (2003).
157. Bergbom, S., Flink, I. K., Boersma, K. \& Linton, S. J. Early psychologically informed interventions for workers at risk for pain-related disability: does matching treatment to profile improve outcome? J. Occup. Rehabil. 24, 446-457 (2014).

158. Linton, S. J. \& Andersson, T. Can chronic disability be prevented? A randomized trial of a cognitive-behavior intervention and two forms of information for patients with spinal pain. Spine 25, 2825-2831 (2000).

159. Linton, S. J., Boersma, K., Janson, M., Svärd, L. \& Botvalde, $M$. The effects of cognitive-behavioral and physical therapy preventive interventions on pain-related sick leave: a randomized controlled trial. Clin. J. Pain 21, 109-119 (2005)

160. Linton, S. J. \& Ryberg, M. A cognitive-behavioral group intervention as prevention for persistent neck and back pain in a non-patient population: a randomized controlled trial. Pain $90,83-90$ (2001).

161. Linton, S. J. \& van Tulder, M. W. Preventive interventions for back and neck pain: what is the evidence? Spine 26, 778-787 (2001).

162. Lamb, S. E. et al. Group cognitive behavioura treatment for low-back pain in primary care: a randomised controlled trial and cost-effectiveness analysis. Lancet 375, 916-923 (2010).

This multicentre RCT reveals that a group cognitive behavioral intervention had a sustained effect on troublesome subacute and chronic low-back pain at a low cost to the health-care provider.

163. O'Sullivan, P. B. et al. Cognitive functional therapy: an integrated behavioral approach for the targeted management of disabling low back pain. Phys. Ther. 98, 408-423 (2018)

164. George, S. Z. et al. A randomized trial of behavioral physical therapy interventions for acute and sub-acute low back pain. Pain 140, 145-157 (2008).

165. O'Sullivan, K., Dankaerts, W., O'Sullivan, L. \& O'Sullivan, P. B. Cognitive functional therapy for disabling nonspecific chronic low back pain: multiple case-cohort study. Phys. Ther. 95, 1478-1488 (2015).

166. Shaw, W. S., Campbell, P., Nelson, C. C., Main, C. J. $\&$ Linton, S. J. Effects of workplace, family and cultural influences on low back pain: what opportunities exist to address social factors in general consultations? Best Pract. Res. Clin. Rheumatol. 27, 637-648 (2013).

167. Shaw, W. S., Feuerstein, M. \& Huang, G. D. in New Avenues for the Prevention of Chronic Musculoskeletal Pain and Disability (ed. Linton, S. J.) 215-235 (Elsevier, 2002).

168. Franche, R.-L. et al. Workplace-based return-to-work interventions: a systematic review of the quantitative literature. J. Occup. Rehabil. 15, 607-631 (2005).

169. Carroll, C., Rick, J., Pilgrim, H., Cameron, J. \& Hillage, J. Workplace involvement improves return to work rates among employees with back pain on long-term sick leave: a systematic review of the effectiveness and cost-effectiveness of interventions. Disabil. Rehabil. 32 607-621 (2010)

170. Bartys, S., Frederiksen, P., Bendix, T. \& Burton, K System influences on work disability due to low back pain: an international evidence synthesis. Health Policy 121, 903-912 (2017).

171. Sennehed, C. P. et al. Early workplace dialogue in physiotherapy practice improved work ability at one-year follow-up: a randomized controlled trial in primary care. Pain 159, 1456-1464 (2018).

172. Bernstein, I. A., Malik, Q., Carville, S. \& Ward, S. Low back pain and sciatica: summary of NICE guidance. BMJ 356, i6748 (2017)

173. Qaseem, A., Wilt, T. J., McLean, R. M \& Forciea, M. A. Noninvasive treatments for acute, subacute, and chronic low back pain: a clinical practice guideline from the American College of Physicians. Ann. Intern. Med. 166, 514-530 (2017).

174. Van Wambeke, P et al. Low back pain and radicular pain: assessment and management - summary KCE https://kce.fgov.be/sites/default/files/atoms/ files/KCE_287C_Low_back_pain_Summary.pdf (2017).

175. Stochkendahl, M. J et al. National Clinical Guidelines for non-surgical treatment of patients with recent onset low back pain or lumbar radiculopathy. Eur. Spine J. 27, 60-75 (2018).

176. Dowell, D., Haegerich, T. M. \& Chou, R. CDC Guideline for prescribing opioids for chronic pain - United States, 2016. JAMA 315, 1624-1645 (2016).

177. Gunter, B. R., Butler, K. A., Wallace, R. L., Smith, S. M. \& Harirforoosh, S. Non-steroida anti-inflammatory drug-induced cardiovascular adverse events: a meta-analysis. J. Clin. Pharm. Ther 42, 27-38 (2017)

178. Hoffmann, T. C. et al. Prescribing exercise interventions for patients with chronic conditions CMAJ 188, 510-518 (2016).

179. Williams, C. M. et al. Efficacy of paracetamol for acute low-back pain: a double-blind randomised controlled trial. Lancet 384, 1586-1596 (2014). This large multicenter reveals that regular or as-needed dosing with paracetamol does not affect recovery time, compared with placebo in acute low-back pain

180. Abdel Shaheed, C., Maher, C. G., Williams, K. A., Day, R. \& McLachlan, A. J. Efficacy, tolerability, and dosedependent effects of opioid analgesics for low back pain: a systematic review and meta-analysis. JAMA Intern. Med. 176, 958-968 (2016). This meta-analysis reveals that for people with chronic low back pain who tolerate the medicine, opioid analgesics provide modest and clinically not important immediate effects, and that evidence on long-term efficacy is lacking and efficacy in acute low back pain is unknown.

181. Enke, O., et al. Anticonvulsants in the treatment of low back pain and lumbar radicular pain: a systematic review and meta-analysis. Can. Med. Assoc. 190, E786-E793 (2018).

182. van Kleef, M. et al. Randomized trial of radiofrequency lumbar facet denervation for chronic low back pain. Spine 24, 1937-1942 (1999).

183. Bernstein, I. A., Malik, Q., Carville, S. \& Ward, S Low back pain and sciatica: summary of NICE guidance. BMJ 356, i6748 (2017).

184. Juch, J. N. S. et al. Effect of radiofrequency denervation on pain intensity among patients with chronic low back pain: the mint randomized clinical trials. JAMA 318, 68-81 (2017).

185. McCormick, Z. L. et al. Guidelines for composing and assessing a paper on the treatment of pain: a practical application of evidence-based medicine principles to the mint randomized clinical trials. Pain Med. 19, 2127-2137 (2018).

186. Provenzano, D. A Buvanendran, A de Leon-Casasola, O. A., Narouze, S. \& Cohen, S. P. Interpreting the MINT randomized trials evaluating radiofrequency ablation for lumbar facet and sacroiliac joint pain: a call from ASRA for better education, study design, and performance. Reg. Anesth. Pain Med. 43, 68-71 (2018)

187. van Kuijk, S. M. J. et al. Flawed study design and incorrect presentation of data negatively impact potentially useful interventional treatments for patients with low back pain: a critical review of JAMA's MinT Study. Pain Pract. 18, 292-295 (2018)

188. Pinto, R. Z., Verwoerd, A. J. H. \& Koes, B. W. Which pain medications are effective for sciatica (radicular leg pain)? BMJ 359, j4248 (2017)

189. Mathieson, S. et al. Trial of pregabalin for acute and chronic sciatica. N. Engl. J. Med. 376, 1111-1120 (2017).

190. Cohen, S. P., Bicket, M. C. Jamison, D., Wilkinson, I. \& Rathmell, J. P. Epidural steroids: a comprehensive, evidence-based review. Reg. Anesth. Pain Med. 38, 175-200 (2013)

191. Van Wambeke, P. et al. Low back pain and radicular pain: assessment and management (Belgian Health Care Knowledge Centre (KCE), Brussels, 2017).

192. Lindstrom, I. et al. The effect of graded activity on patients with subacute low back pain: a randomized prospective clinical study with an operant-conditioning behavioral approach. Phys. Ther. 72, 279-290; discussion 291-293 (1992).

193. Kamper, S. J. et al. Multidisciplinary biopsychosocial rehabilitation for chronic low back pain: Cochrane systematic review and meta-analysis. BMJ 350, h444 (2015).

194. Waterschoot, F. P. et al. Dose or content? Effectiveness of pain rehabilitation programs for patients with chronic low back pain: a systematic review. Pain $\mathbf{1 5 5}$ 179-189 (2014)

195. Vlaeyen, J. W. \& Morley, S. Cognitive-behavioral treatments for chronic pain: what works for whom? Clin. J. Pain 21, 1-8 (2005)

196. Vlaeyen, J. W., Morley, S., Linton, S., Boersma, K. $\&$ De Jong, J. Pain-Related Fear: Exposure-Based Treatment for Chronic Pain (IASP Press, 2012).

197. Lopez-de-Uralde-Villanueva, I. et al. A systematic review and meta-analysis on the effectiveness of graded activity and graded exposure for chronic nonspecific low back pain. Pain Med. 17, 172-188 (2016). 
198. Bailey, K. M., Carleton, R. N., Vlaeyen, J. W. \& Asmundson, G. J. Treatments addressing pain-related fear and anxiety in patients with chronic musculoskeletal pain: a preliminary review. Cogn. Behav. Ther. 39 46-63 (2010).

199. Goossens, M. E. et al. Is exposure in vivo costeffective for chronic low back pain? A trial-based economic evaluation. BMC Health Serv. Res. 15, 549 (2015).

200. Schork, N. J. Personalized medicine: time for one-person trials. Nature 520, 609-611 (2015).

201. de Jong, J. R. et al. Fear of movement/(re)injury in chronic low back pain: education or exposure in vivo as mediator to fear reduction? Clin. J. Pain 21, 9-17 discussion 69-72 (2005).

202. Vlaeyen, J. W., de Jong, J., Geilen, M., Heuts, P. H. \& van Breukelen, G. Graded exposure in vivo in the treatment of pain-related fear: a replicated single-case experimental design in four patients with chronic low back pain. Behav. Res. Ther. 39, 151-166 (2001).

203. Buchbinder, R. et al. Low back pain: a call for action Lancet 391, P2384-P2388 (2018).

204. Blyth, F. M. \& Huckel Schneider, C. Global burden of pain and global pain policy-creating a purposeful body of evidence. Pain 159 (Suppl. 1), S43-S48 (2018).

205. Williams, C. M. et al. Low back pain and best practice care. A survey of general practice physicians. Arch. Intern. Med. 70, 271-277 (2010)

206. Gross, D. P. et al. Evaluation of a Canadian back pain mass media campaign. Spine $35,906-913$ (2010).

207. Buchbinder, R., Jolley, D. \& Wyatt, M. 2001 Volvo award winner in clinical studies: effects of a media campaign on back pain beliefs and its potential influence on management of low back pain in general practice. Spine 26, 2535-2542 (2001).

208. Coudeyre, E. et al. General practitioners' fear-avoidance beliefs influence their management of patients with low back pain. Pain 124, 330-337 (2006).

209. Bishop, A., Thomas, E. \& Foster, N. E. Health care practitioners' attitudes and beliefs about low back pain: a systematic search and critical review of available measurement tools. Pain 132, 91-101 (2007).

210. Jenkins, H. J. et al. Effectiveness of interventions designed to reduce the use of imaging for low-back pain a systematic review. CMAJ 187, 401-408 (2015).

211. Nicholl, B. et al. Premorbid psychosocial factors are associated with poor health-related quality of life in subjects with new onset of chronic widespread pain. Results from the EPIFUND study. Pain 141, 119-126 (2009).

212. Jaremo, P., Arman, M., Larsson, B. \& Gottberg, K. Illness beliefs among patients with chronic widespread pain-associations with self-reported health status, anxiety and depressive symptoms and impact of pain. BMC Psychol. 5, 24 (2017).

213. Fredheim, O. et al. Chronic non-malignant pain patients report poor health related quality of life as palliative cancer patients. Acta. Anaesthesiol. Scand. 52, 143-148 (2008)

214. Snelgrove, S. \& Liossi, C. Living with chronic low back pain: a metasynthesis of qualitative research. Chronic IIn. 9, 283-301 (2013).

215. MacNeela, P., Doyle, C., O'Gorman, D., Ruana, N. \& McGuire, E. Experiences of chronic low back pain: a meta-ethnography of qualitative research. Health Psychol. Rev. 9, 63-82 (2015).

216. Bunzli, S., Watkins, R., Smith, A., Schutze, R. \& O'Sullivan, P. Lives on hold: a qualitative synthesis exploring the experience of chronic low-back pain. Clin. J. Pain 9, 907-916 (2013).

217. Keeley, P. et al. Psychosocial predictors of health related quality of life and health services utilisation in people with chronic low back pain. Pain 135 , 142-150 (2008)

218. Cedraschi, C., Luthy, C., Allaz, A., Herrmann, F. \& Ludwig, C. Low back pain and health-related quality of life in community-dwelling older adults. Eur. Spine $J$. 25, 2822-2832 (2016)

219. Ware, J. E. et al. The factor structure of the SF-36 Health Survey in 10 countries: results from the IQOLA Project. International Quality of Life Assessment. J. Clin. Epidemiol. 51, 1159-1165 (1998).

220. Overmeer, T. \& Boersma, K. What messages do patients remember? Relationships among patients' perceptions of physical therapists' messages, patient characteristics, satisfaction, and outcome. Phys. Ther 96, 275 (2016).

221. Ferreira, M. L. \& de Luca, K. Spinal pain and its impact on older people. Best Pract. Res. Clin. Rheumatol. 31, 192-202 (2017)

222. Zorina-Lichtenwalter, K., Meloto, C. B., Khoury, S. $\&$ Diatchenko, L. Genetic predictors of human chronic pain conditions. Neuroscience 338, 36-62 (2016).

223. Houben, R. M. et al. Health care providers' orientations towards common low back pain predict perceived harmfulness of physical activities and recommendations regarding return to normal activity. Eur. J. Pain 9, 173-183 (2005).

224. Rainville, J., Carlson, N., Polatin, P., Gatchel, R. J. \& Indahl, A. Exploration of physicians' recommendations for activities in chronic low back pain. Spine $\mathbf{2 5}$, 2210-2220 (2000).

225. Rutten, B. P. et al. Resilience in mental health: linking psychological and neurobiological perspectives. Acta Psychiatr. Scand. 128, 3-20 (2013).

226. Baliki, M. N., Mansour, A. R., Baria, A. T. $\&$ Apkarian, A. V. Functional reorganization of the default mode network across chronic pain conditions. PLOS ONE 9, e 106133 (2014).

227. Pereira, T. V., Horwitz, R. I. \& loannidis, J. P. Empirical evaluation of very large treatment effects of medical interventions. JAMA 308, 1676-1684 (2012).

228. Fordham, B., Ji, C., Hansen, Z., Lall, R. \& Lamb, S. E. Explaining how cognitive behavioral approaches work for low back pain: mediation analysis of the back skills training trial. Spine 42, E1031-E1039 (2017).

229. Whittle, R., Mansell, G., Jellema, P. \& van der Windt, D. Applying causal mediation methods to clinical trial data: what can we learn about why our interventions (don't) work? Eur. J. Pain 21, 614-622 (2017).

230. Zhang, Z. et al. Causal mediation analysis in the context of clinical research. Ann. Transl Med. 4, 425 (2016).

231. Foster, N. E., Hill, J. C., O’Sullivan, P. \& Hancock, M. Stratified models of care. Best Pract. Res. Clin. Rheumatol. 27, 649-661 (2013)

232. Onghena, P. \& Edgington, E. S. Customization of pain treatments: single-case design and analysis. Clin. J. Pain 21, 56-68; discussion 69-72 (2005).

233. Vohra, S. N-of- 1 trials to enhance patient outcomes: identifying effective therapies and reducing harms, one patient at a time. J. Clin. Epidemiol. 76, 6-8 (2016).

234. Kratochwill, T. R. et al. What works clearinghouse: single-case designs technical documentation. ERIC https://files.eric.ed.gov/fulltext/ED510743.pdf (2010).

235. Tate, R. L. et al. Revision of a method quality rating scale for single-case experimental designs and n-of-1 trials: the 15-item Risk of Bias in N-of-1 Trials (RoBiNT) Scale. Neuropsychol.Rehabil. 23, 619-638 (2013).

236. Amorim A. B. et al. Integrating mobile health and physical activity to reduce the burden of chronic low back pain trial (IMPACT): a pilot trial protocol. BMC Musculoskelet. Disord. 17, 36 (2016).

237. Buhrman, M., Nilsson-Ihrfeldt, E., Jannert, M. Strom, L. \& Andersson, G. Guided internet-based cognitive behavioural treatment for chronic back pain reduces pain catastrophizing: a randomized controlled trial. J. Rehabil. Med. 43, 500-505 (2011).

238. de la Vega, R. \& Miro, J. mHealth: a strategic field without a solid scientific soul. A systematic review of pain-related apps. PLOS ONE 9, e 101312 (2014).

239. Thorn, B. E. et al. Literacy-adapted cognitive behavioral therapy versus education for chronic pain at low-income clinics: a randomized controlled trial. Ann. Intern. Med 168, 471-480 (2018).

240. Mi, H. et al. PANTHER version 11: expanded annotation data from gene ontology and reactome pathways, and data analysis tool enhancements. Nucleic Acids Res. 45, D183-D189 (2017).

241. Institute for Health Metrics and Evaluation. Global Burden of Disease Study 2016. https://vizhub. healthdata.org/gbd-compare/ (2016).

242. Herlin, C. et al. Modic changes-Their associations with low back pain and activity limitation: A systematic literature review and meta-analysis. PLOS ONE 13 e0200677 (2018).

\section{Acknowledgements}

J.W.S.V. is supported by the Research Foundation Flanders, Belgium (FWO Vlaanderen: \#G001818N and \#G071118N), the 'Asthenes' long-term structural funding-Methusalem grant by the Flemish Government, Belgium (METH/15/011) and the National Institute for Health and Disability Insurance (NIHDI: \#2018-00047). C.G.M. is supported by the National Health and Medical Research Council of Australia (APP1103022, APP1113532 and APP1134856). C.B.M. is supported the Louise and Alan Edwards Foundation. L.D. is supported by the Canadian Excellence Research Chair fund (grant CERC 09).

\section{Author contributions}

Introduction (J.W.S.V. and C.G.M.); Epidemiology (C.G.M and B.K.); Mechanisms/pathophysiology (J.W.S.V., K.W., C.B.M. L.D. and M.C.B.); Diagnosis, screening and prevention (C.G.M., J.V.Z. and S.J.L.); Management (J.W.S.V., C.G.M., J.V.Z. and S.J.L.); Quality of life (M.G. and J.W.S.V.); Outlook (J.W.S.V. and M.G.); Overview of the Primer (J.W.S.V.).

\section{Competing interests}

J.W.S.V. is chief investigator or associate investigator on mul tiple previous and current research grants from Belgium, including the Flemish Government, Research Foundation Flanders (FWO Vlaanderen) and the National Institute for Health and Disability Insurance (NIHDI). He has received travel expenses for speaking at conferences from the professional associations hosting the conferences and has received honoraria for reviewing grants from government grant agencies and honoraria for marking theses from universities. C.G.M. is chief investigator or associate investigator on multiple previous and current research grants from government research agencies from Australia (for example, the National Health and Medical Research Council (NHMRC) of Australia), Brazil (for example, São Paulo Research Foundation (FAPESP)) and the Netherlands (for example, the Netherlands Organisation for Health Research and Development (ZonMW)). For the past 12 years, his salary has been covered by research fellowships from Australia's NHMRC or the Australian Research Council. His research has also received funding from philanthropic (for example, Arthritis Australia) and government agencies (for example, NSW WorkCover). He has received travel expenses for speaking at conferences from the professional associations hosting the conferences and has received honoraria for talks from professional associations and the industry hosting the talks, honoraria for reviewing grants from government grant agencies and honoraria for marking theses from the relevant university. C.G.M. received supplementary industry funding for two investigator-initiated NHMRC-funded trials. The first trial (PACE) had co-funding from GlaxoSmithKline. Pfizer provided the study medicine for the second trial, PRECISE, at no cost, but provided no other funding. J.V.Z. is a member of the Executive Board of the World Institute of Pain (WIP). M.G. declares that she is bound by confidentiality agreements that prevent her from disclosing her competing interests in this work. S.J.L. is chief investigator or associate investigator on multiple previous and current research grants from Sweden, including Vetenskapsrådet, FORTE, Riksbankensjubileumsfond, REHSAM and Örebro University. He has received travel expenses for speaking at conferences from the professional associations hosting the conferences and has received honoraria for reviewing grants and giving educational lectures. All other authors declare no competing interests.

\section{Publisher's note}

Springer Nature remains neutral with regard to jurisdictional claims in published maps and institutional affiliations.

\section{Reviewer information}

Nature Reviews Disease Primers thanks K. Dunn, S. George, C. Leboeuf-Yde and G. L. Moseley, and other anonymous reviewer(s), for their contribution to the peer review of this work.

\section{Supplementary information}

Supplementary information is available for this paper at https://doi.org/10.1038/s41572-018-0052-1.

RELATED LINKS
Örebro Musculoskeletal Pain Screening Questionnaire
(ÖMPSQ): https://www.oru.se/english/research/research-
environments/hs/champ/questionnaires/
STarTBack Screening Tool: https://www.keele.ac.uk/sbst/
startbacktool/

